\title{
Die Ursachen der geschlechtlichen Differenzirung im Bienenstaat.
}

\author{
(Ein Beitrag zur Vererbungsfrage.) \\ Von
}

Ferd. Diekel, Darmstadt.

(Mit 1 Textfigur.)

\section{a) Einleitung.}

Im Hinblick auf die enorme Ausdehnung einer jeden naturwissensehaftlichen Disciplin halte ich mich nicht zu der Annahme berechtigt, dass Physiologen von Beruf den "Anatomischen-" oder "Zoologischen Anzeiger" lesen, welche sich beide schon mit der zu besprechenden Angelegenheit befasst haben. Ich muss daher zunächst die leitenden Gesichtspunkte, wenigstens mit Bezug auf den Hauptpunkt der nachfolgenden Ausführungen, dadurch zu präcisiren suchen, dass ich denselben eine kurzgefasste historische Skizze vorausgehen lasse. Es handelt sich in der Hauptsache um den empirischen Nachweis des Befruchtetseins normaler Drohneneier im Gegensatz zu der bisher als richtig angenommenen Behauptung, dieselben seien unbefruchtet.

Der grosse Natur- und Bienenforscher Réa u m ur sprach seiner Zeit auf Grund der von ihm beobachteten Thatsachen des Bienenlebens in folgerichtiger Ableitung die Ansicht aus: Die Mutterbiene einer Honigbienenkolonie ist befähigt, dreierlei verschieden beschaffene Eier abzulegen, denn aus denselben entwickeln sich dreierlei, sowohl hinsichtlich der Organe wie der Triebe, durchaus von einander abweichende Thierformen. Die Arbeitsbienen, welche die dreierlei Zellenformen errichten, in denen sich diese dreierlei Thierformen entwickeln, müssen auf irgend welchem Wege aber wissen können, wievjele Eier jeder Art die Mutterbiene legen kann, und wann sie dieselben legen will, denn sie errichten immer die entsprechenden 
Die Ursachen der geschlechtlichen Differenzirung im Bienenstaat.

Zellenformen zur rechten Zeit in derjenigen Anzahl; wie sie die Mutterbiene besetzen will.

Dieser logisch durchaus richtige, weil durch Thatsachen gestützte Schluss musste solange als einwandfrei zu Recht bestehen, als man nicht durch andere Thatsachen des Bienenlebens das Irrige desselben nachweisen konnte.

Der Nachweis der Irrigkeit desselben war dem ausgezeichneten deutschen Bienenforscher Schirach vorbehalten. Er zeigte durch den Versuch, dass die Arbeiter der Bienenkolonie zu allen Zeiten des Jahres befähigt sind, aus jeder Arbeiterlarve, die in einer noch offenen Zelle lagert, eine Mutterbiene heranbilden zu können. Damit war die Annahme einer versehiedenen Veranlagung der Eier für Arbeiter und Mutterthiere hinfällig geworden.

Ungefähr zur selben Zeit entdeckte der Bienenbeobachter Ri e m die Fähigkeit der begattungs unfähigen Arbeiter, unter gestörten, krankhaften Zuständen ebenfalls Eier produciren zu können. Aus solchen Eiern gehen jedoch, wie ganz ausser Zweifel feststeht, unter allen in der Bienenkolonie möglichen Verhältnissen, stets nur männliche Bienenformen hervor. Hierzu gesellte sich die weitere Frfahrung: dass auch die nicht zur Begattung gelangende Mutterbiene, wenn sie nach langer Zeit dennoch in die Eierlage eintritt, sich also abnorm entwickelt hat, ebenfalls nur Eier producirt, die unter allen Umstäuden Männchen ergeben. Ferner wurde in jener Zeitperiode das Receptaculum seminis der Insectenweibchen entdeckt, und auf Grundlage dieses gegebenen Beobachtungsmaterials stellte nun der Bienenwirth Dzierzon im Jahre 1845, gestützt auf die hervorgehobenen Erscheinungen krankhafter Zustände in der Bienenkolonie, die ebenso befremdende wie inconsequente Hypothese auf:

Die Mutterbiene der Bienenkolonie ist befähigt, das Geschlecht der Nachkommen zu bestimmen, indem sie Eier von zweierlei Beschaffenheit zu legen vermag. Die Drohneneier bedürfen der Befruchtung nicht, und die Eier, aus denen Männchen entstehen sollen, entzieht sie dem Einfluss des Samenhalters. Lässt die Mutterbiene jedoch die Besamung der Eier zu, so entstehen aus ihnen Arbeitsbienen und in deren vollkommener Ausbildung Mutterbienen.

Den Beweis für die Zulässigkeit dieser Annahme blieb Dzi erzon bis auf den heutigen Tag schuldig, da er Versuche mit den Bienen zu diesem Zweck niemals angestellt hat. Die einzige Stütze für seine Ansicht glaubte er durch die Erscheinungen bei Kreuzungs- 
versuchen zwischen italienischen, gelben und deutschen, dunkelgefärbten Bienen gewonnen zu haben.

Nach seinen Angaben wies die Kreuzung zwischen italienischen Müttern und deutschen Drohnen, oder umgekehrt, zwischen deutschen Müttern und italienischen Männchen, stets nur Männchen von der Farbe der Mutter auf, während die Arbeitsbienen hinsichtlich der Färbung die Kreuzungsmerkmale beider Eltern trugen. Allein schon damals traten Bienenwirthe, wie u. a. der als genauer Bienenbeobachter hochgeschätzte $\mathrm{O}$. Rothe, dieser Behauptung entgegen. Letzterer schreibt bereits in "Bienenzeitung" 1856 , S. 55, u. a. "Dzierz on sagt, dass alle italienischen Mütter, gleichviel ob echte oder Bastarde, bei ihm auch nur italienische Drohnen hervorgebracht. Bei mir war dies nicht der Fall," und nun folgten die Belege.

Dzierzon muss indessen selbst entgegengesetzte Erfahrungen gemacht haben, denn im „Bienenfreund " führte er zu jener Zeit aus: „Kann vielleicht, wenn auch das samengefüllte Bläschen dem Ei den Lebenskeim zu der Drohne nicht einpflanzt, doch ein gewisser Anhauch davon auf die Art und Farbe bestimmend wirken." Die Beweise gegen die Richtigkeit der Dzierzon'schen Behauptung häuften sich immer mehr, und verweise ich besonders auf die Ausführungen von $\operatorname{Perez} \mathrm{z}^{1}$ ) und $\mathrm{J}_{0} \mathrm{hn} \mathrm{L}_{0 \mathrm{we}} \mathrm{e}^{2}$ ).

Die gleichen widersprechenden Versuchsergebnisse habe auch ich schon bei meinem allerersten Versuche erzielt. Mulot und ich stellten durch zu vielen Dutzenden angestellte Versuche ferner das bemerkenswerthe Resultat fest, dass man in ausserordentlich zahlreichen Fällen unter den Arbeitsbienen der ersten Kreuzung zwischen italienischen Weibchen und deutschen Männchen, auch bei genauestem Vergleich, Färbungsabweichungen vom italienischen Typus überhaupt nicht nachweisen kann. Wohl aber kann man die stattgehabte Kreuzung in zahlreichen Fällen dieser Art durch sorgfältigen Vergleich der Drohnen constatiren.

Beachtenswerth ist ferner die auch jedem Handelsbienenzüchter

1) Perez, Sur la poute de l'abeille mère et la théorie de Dzierzon. Compt. rend. Ac. Soc. tom. 87 Nr. 11 p. 408-410. Ferner: Sur la poute de l'abeille mère et la théorie de Dzierzon. Ann. Scienc. Nat. (6) tom. 7 Art. 18 (p. 22).

2) Observations on Dzierzons Theory of Reproduction in the HonneyBee; in Transact. of the Ent. Soc. of London vol. 5 Art. 24. p. 547-562. 1865-67. 
bekannte Erscheinung, dass man auf derselben echt italienischen Brutwabe zu gleicher Zeit in demselben Stock Mutterbienen von der allerverschiedensten Färbung: vom feinsten italienischen Gelb der italienischen bis zum tiefsten Schwarz der deutschen Bienenweibchen, erzielt.

Nichtsdestoweniger gilt diese dureh Reihen von Erfahrungsbeweisen längst widerlegte Ansicht Dzierzon's in maassgebenden zoologischen Fachkreisen denuoch als über allen $Z$ weifel erhaben. Sie gilt desshalb als sicher erwiesen, weil im Jahre 1855 v. Siebold durch seine Bieneneistudien zu Seebach, mittels einer heute nicht mebr üblichen Quetschungsmethode, in Eiern, aus Bienenzellen entnommen, Sperma auffand, solches aber nicbt entdeckte in Eiern, welche Drohnenzellen entstammten.

Als ich jedoch in der "Nördlinger Bienenzeitung" 1897 S. 249, den Nachweis erbrachte, dass nach heutiger Kenntniss der Entwicklungsvorgänge im $\mathrm{Ei}$ jene Untersuchungen der beweisenden Kraft ermangeln, da die nicht conservirten, untersuchten Eier aus Drohnenzellen nach v. Siebold's eigenen Angaben ein Alter von ètwa 12 Stunden batten, da wurde Weismann auf meine in genannter Zeitschrift veröffentlichten Versuchsergebnisse aufmerksam, welche die Annahme unabweisbar machten:

Die begattete Mutterbiene legt nicht Eier von dreierlei noch zweierlei, sondern nur solche von einerlei Beschaffenheit, d. h. befruchtete Eier, in alle Zellen ab.

Die Ursache, wesswegen aus den einen Eiern Arbeiter, aus anderen Drohnen und aus noch anderen richtige Weibchen entstehen, liegt nicht in der Mutterbiene, sondern in Beeinflussungen, welche die abgelegten Eier von Seiten der Arbeiterinnen erfahren.

Dies schien mir aus den weiter unten angeführten Versuchen, die sich in letzter Zeit noch sehr vermehrt baben, hervorzugehen.

Weismann hatte die Güte, mich zur Einsendung von 4-5 Eiern zu veranlassen, und hoffte damit den Beweis der Richtigkeit meiner Annahme zu erbringen. Er veranlasste seine Schüler Paulcke und Petrunkewitsch zur Vornahme dieser Untersuchungen. Aus den 4-5 Eiern wurden aber im Laufe zweier Jahre fast ebenso viele Tausende, clie allmählich nach Freiburg wanderten, und das Fndergebniss lautete: „Die von der Königin 
in die Drohnenzellen abgesetzten Eier sind immer unbefruchtet."1)

Nach den Befunden Petrunkewitsch's tritt in den Eiern, welche Arbeiterinnen ergeben, immer eine deutliche Spermastrahlung auf; sie fehlt dagegen in den Eiern, welche Drohnenzellen entnommen sind. Hieraus schliesst er, dass nur in die Arbeiter- und Mutterbieneneier Samenfäden eindringen, dass aber die Drohneneier unbefruchtet seien. Nun ist aber nach Petrunkewitsch's eigener Aussage das Spermakorn so klein, dass es von anderen Pünktchen im Ei nur dann unterschieden werden kann, wenn es von einer Strahlung umgeben ist. Der Schluss, dass in den Drohneneiern kein Sperma eingedrungen sei, ist also nicht bindend. Da über die Bedeutung der Strahlung die Ansichten noch auseinandergehen, so besteht die Möglichkeit, dass die Drohneneier gerade so gut befruchtet sind wie die übrigen Eier, dass aber die Strahlung aus irgend welchen Gründen ausbleibt.

Die Morphologen, denen das Mikroskop als letzte Instanz gilt, scheinen die Frage nach der Geschlechtsentstehung bei den Bienen seit Erscheinen der Arbeit Petrunke witsch's endgültig als erledigtanzusehen. Ebenso verhält es sich mit der Mehrzahl der Bienenforscher und Bienenwirthe, welche so von der Richtigkeit der Dzierzon'schen Lehre eingenommen sind, dass sie sich, mit wenigen Ausnahmen, guten Gründen vollkommen verschliessen. (Auf die von Dzierzon in der "Leipziger Bienenzeitung" 1898 mir gegenüber erhobenen Einwände einzugehen, verzichte ich.)

Nach meiner Meinung kann die Entscheidung in dieser theoretisch so wichtigen Frage durch's Mikroskop nicht erbracht werden, sondern nur durch experimentelle Untersuchungen. Ich habe mich daher entschlossen, meine, mir durchaus die Richtigkeit meiner Ansicht beweisenden Experimente ${ }^{2}$ ) hier in der Hauptsache zusammen zu stellen und dem Urtheil der Physiologen zu unterbreiten.

\section{b) Ausführung.}

Seit Anerkennung der Dzierzon'schen Entwicklungslehre der Bienenwesen hat man sich daran gewöhnt, die Arbeitsbienen als

1) Petrunkewitsch, Die Richtungskörper und ihr Schicksal im befruchteten und unbefruchteten Bienenei. Zoologische Jahrbücher Bd. 14 S. 603. 1901.

2) Ein Theil meiner Versuche ist von den Herren Petilli ot (Heiligenwald), Mul ot (Darmstadt', Me yer (Gadernheim), Heck (Duderod), Hen sel (Hirzenhain), und N. Ludwig (Biewer) mit Erfolg nachgeprüft worden. 
verkümmerte Weibehen zu betrachten. Nichts ist aber verkehrter als das, denn diese Auffassung schliesst gleichzeitig die Vorstellung mit ein, bei der Arbeiterin seien die Eigenschaften des Weibchens graduell weniger entwickelt. Dem gegenüber muss hervorgehoben werden, dass die Arbeitsbiene ein ganz anderes Thier mit völlig anderen, ja, gerade entgegengesetzten, scharf ausgesprochenen Trieben ist, ausgerüstet mit Organen, die trotz ihrer Unentbehrlichkeit für die Colonie dem Weibchen theilweise sogar gänzlich mangeln.

Ohne auf die Anatomie der Biene eingehen zu wollen, muss ich doch hier auf einige besonders in die Augen fallenden Unterschiede hinweisen.

Die Mutterbiene besitzt zwar, wie die Arbeiterin, einen Rüssel, aber nur von etwa halber Länge, wie von weniger complicirtem Bau, der erfahrungsgemäss zum Einsammeln von Nektar aus den Blüthen untauglich ist.

Die Arbeiterin ist ausgestattet mit den so charakteristischen Sammelapparaten für Blüthenstaub. Die Mutterbiene besitzt weder eine Spur von "Sammelkörbchen" noch "Pollenbürsten" an den Schienen des dritten Fusspaares. Sie ist zum Einsammeln von Blüthenstaub unfähig.

Die Existenz der Bienencolonie ist bekanntlich an die Fähigkeit der Wachsproduction gebunden. Zu dem Zweck haben die Arbeiterinnen besondere Apparate an den Bauchringen des Hinterleibs. Die Mutterbiene aber hat die "Wachstaschen" der Arbeiter nicht. An der gleichen Körperstelle zeigt sie Verhornungen, und sie ist daher zur Wachsproduction unfähig.

Die Mutterbiene besitzt zwar dieselben Kopf- und Brustdrüsen wie die Arbeiterin, allein sie functioniren bei ihr zum Theil wenig oder gar nicht, während sie bei der Arbeiterin weit vollkommener ausgebildet sind und kräftig functioniren ${ }^{1}$ ) u. s. w. u. s. w.

Haben wir in der Arbeitsbiene somit ein durchans anderes Thier vor uns, so werden wir, geg'enüber den heutigen Vorstellungen über Wesen und Bedeutung der Chromosomen als Vererbungsträger, auf die Annahme hingewiesen, diese Eigensehaften der Arbeiterinnen seien Erbstücke ihrer Väter, der Drohnen. Das ist aber unzutreffend, denn die betreffenden Körperorgane und dadurch bedingten Triebe

1) Schiemenz, Ueber Speicheldrüsen. Zeitschrift für wissenschaftl. Zool. Bd. 38, Jahrg. 1883. 
der Arbeiter mangeln auch ihnen gänzlich. Daher bereiten uns denn die Bienen nicht unerhebliche Verlegenheiten, so bald wir versuchen, die bei ihnen vorliegenden Thatsachen vom Standpunkt der heute herrschenden Anschauungen aus zu beurtheilen.

Treten wir zu diesem Zweck den Thatsachen des Bienenlebens näher.

Einer Bienencolonie, welche ausschliesslich Arbeitsbienen in den entsprechenden Zellen heranbildet, die also weder brutbesetzte Mutternoch Drohnenzellen in Pflege hat, nehme man die Mutterbiene weg. Dieser Störungseingriff hat nach einiger Zeit grosse Unruhe der Thiere und damit Wärmeerhöhung im Stock zur Folge. Das n u r vorhandene Ei- und Larvenmaterial für Arbeiterinnen wird von nun ab zum Theil nach anderen Richtungen hin beeinflusst. Den Erfoly. constatire man nach etwa zehn Tagen.

Man wird dann in den allermeisten Fällen neben und zwischen regelrecht verschlossenen Arbeiterzellen auch einige, nach abwärts gerichtete, der Eichel ähnliche Zellen bemerken. Die einliegenden Larven entwickeln sich erfahrungsgemäss zu echten Mutterbienen. Aber noch mehr. In vielen Fällen wird man auch einige, die Höhe von geschlossenen Arbeiterzellen überragende, geschlossene Zellen vorfinden. Eine Erscheinung, die vor Wegnahme der Mutterbiene im ganzen Stock nicht zu constatiren war. Diese Zellen enthalten Drohnen, die für die Regel zierlicher gebaut sind, als die in Drohnenzellen heranwachsenden.

Nachdem ich auf diese Erscheinung aufmerksam gemacht hatte, wurde dieselbe durch zahlreiche, zuverlässige Bienenwirthe anderwärts als richtig bestätigt. Diese Drohnen müssen aber aus Material entstanden sein, aus dem sich bei normaler Weiterentwicklung Arbeiter gebildet hätten, denn der aufmerksame Blick in die nicht geschlossenen Zellen belehrt uns darüber, dass nach dem Abgang der Mutterbiene andere Eier in der Kolonie nicht abgelegt wurden. Nur in sehr seltenen Fällen bemerkt man unter solehen Umständen nach zehn Tagen schon einige Eier, die von den Arbeitern selbst herrühren. Allein sie können die Herkunft der erzielten Drohnen als Producte aus Eiern der weggenommenen Mutterbiene absolut nicht in Frage stellen. ${ }^{1}$ )

1) In weiterer Ausführung werde ich eine Modification dieses Verfahrens vorbringen und besprechen, welche die hier schon festgestellte Erscheinung in noch weit auffallenderer Weise zur Darstellung bringt. 
Diese Thatsachen des Bienenlebens, welche die Gegner meiner Anschauungen durch alle möglichen Wendungen und Drehungen wegzuleugnen suchen, belehren uns aber dahin:

Vom Standpunkt der Bienenforschung aus ist die Anschauung nicht richtig, dass der Charakter der Nachkommenschaft durch die Befruchtung an sich fest bestimmt wird.

Bieten uns nun auch die dargelegten Erscheinungen wohl keinen directen Anlass, an der Richtigkeit der Anschaung zu zweifeln, was in den beiden Keimpunkten nicht vorgebildet sei, das könne auch als Eigenschaft der Nachkommen nicht in die Erscheinung treten, so will mir dennoch die heutige Auffassung nach dieser Richtung hin als ein starrer Ausdruck logischer Consequenzen erscheinen, der sich mit dem Fluss im Werdeprocess, mit der hervorgehobenen Umbildungsfähigkeit der Embryonen in Bienenzellen, nicht wohl in Finklang bringen lässt.

Die zunächstfolgenden Versuche sollen dazu dienen, Anhaltspunkte zu gewinnen zur Beurteilung des Verhältnisses, in welchem die Arbeitsbienen zu den Geschlechtsthieren der Bienencolonie stehen.

\section{Versuch I.}

In ein bienen-, nicht luftdicht verschliessbares, mit ausreichend Honig und Blütenstaub in Bienenwaben ausgerüstetes Kästchen, bringe man nebst einer Mutterbiene 150 bis 200 Arbeitsbienen und bewahre dasselbe in einer Durchschnittstemperatur von 10 bis $15^{\circ} \mathrm{C}$., möglichst im Dämmerlichte, auf. Unter diesen Bedingungen werden die Thiere Monate lang am Leben erhalten und Wochen lang selbst dann, wenn sie öfter wechselnden Temperatureinflüssen ausgesetzt werden. Auch eintretende Brutpflege ändert das Resultat im Wesentlichen nicht $a b$.

\section{Versuch II.}

Derselbe weicht von I nur darin ab, dass man Waben reicht, welche nur Honig und keinen Blütenstaub enthalten. Das Ergebniss fällt im Ganzen so aus wie bei Versuch I. Legt jedoch das Mutterthier Eier ab, und die Bienen pflegen sie, so gehen sie weit eher zu Grunde. Für die Regel zehren sie die Eier jedoch auf und ebenso die Larven nebst ihrer Futtersubstanz, wenn bald nach Beginn des Versuchs wirklich einige zu Stande kamen. Nach dem Aufzehren der Eier und Larven legt das Mutterthier nur noch selten oder gar nicht mehr. 
Versuch III.

Unter gleichen Bedingungen wie Versuch I bringe man 150 bis 200 Arbeitsbienen mit einigen Bienenmännchen zusammen. Die Arbeitsbienen werden sich namentlich bei höherer einwirkender Temperatur zwar sehr erregt zeigen, und in Folge hiervon gehen oft mehrere bald zu Grunde, allein im Ganzen ist der Erfolg dem von Versuch I gleich. Auch die Männchen bleiben lange am Leben.

\section{Versuch IV.}

Wieder unter den angegebenen Bedingen von Versuch I sperre man ein Bienenweibchen mit 150 bis 200 Bienenmännchen zusammen. Die Thiere zeigen in ihrem Verhalten keinerlei auffallende Erregungen. Allein oft schon nach Stunden finden wir einzelne tot, sicherlich aber die ganze Gesellschaft nach $3 \times 24$ Stunden. Bei dieser Gelegenheit kann man beobachten, dass Weibehen und Männchen zwar Honig aus den Zellen aufnehmen können, nicht aber auch Blüthenstaub $\mathrm{zu}$ verzehren vermögen, auf den sie, wie es scheint, überhaupt nicht reagiren.

Vergleichen wir zunächst Versuchsergebniss II und IV mit einander, so geht daraus vor Allem hervor: Die im Honig enthaltenen Kohlehydrate und geringen Mengen von Eiweissstoffen reichen zwar aus zur Erhaltung des Lebens der Arbeitsbiene an sich und der von ihnen gefütterten Mutterbiene, nicht aber auch zur Erhaltung des Lebens der Geschlechtsthiere ohne Mitwirkung der Arbeiter. Männchen und Weibchen zehren Honig, sterben aber dennoch sehr bald. Ihre Organisation ist auf Aufnahme chemisch anders zusammengesetzter Verbindungen eingerichtet, die sie aber selbst nicht zu produciren vermögen, weil sie zur Aufnahme von Blüthenstaub unfähig sind.

Die Geschlechtsthiere der Honigbiene sind somit auf Darreichung solcher Verbindungen angewiesen, wie sie im Körper der Arbeitsbienen erzeugt und mittelst deren Mundtheile ihnen zugeführt werden.

Welcher Art sind nun diese Verbindungen?

Zunächst lehrt Versuch IV überzeugend, dass die landläufige Ansicht irrig ist, als ob es sich beim Füttern der Mutter- durch die Arbeitsbiene um Uebertragung von Honig handle. Vermag doch iler Honig nicht einmal deren nacktes Leben zu erhalten, um wieviel weniger die erstaunlichen Lebensleistungen der Mutterbiene an Eierproduction $\mathrm{zu}$ bewirken. Wohl aber müssen die Uebertragungssubstanzen solche chemische Verbindungen in reicher Menge enthalten, 
welche zum Aufbau von Eizellen erforderlich sind. Das beweist die ausserordentliche Productionsfähigkeit des Mutterthiers an Eiern, der nur eine verschwindend geringe Ausscheidung durch den After gegenübersteht, die von den Arbeitern wieder aufgezehrt wird und daher ebenfalls noch dem Bienenorganismus bekömmliche Substanzen enthalten muss. Durch speciell auf Prüfung der Leistungsfähigkeit der Mutterbiene als Eiermaschine hin vorgenommene Versuche habe ich wiederholt festgestellt, dass die rüstige Mutter innerhalb 24 Stunden über 8000 relativ grosse Eier ablegen kann. ${ }^{1}$ ) Soviel steht fest: D ie Mutterbiene vermag weder zu leben noch Eier zu produciren, ohne Aufnahme von Bildungssubstanzen, welche im Organismus der Arbeitsbiene bereits eine weitgehende chemische Umgestaltung. erfahren haben und von hohem Wert als Zellenbildungstoffe sein müssen.

Die directe und ausschliessliche Betheiligung der Arbeitsbiene am Aufbau und der Gestaltung der Nachkommen tritt mit dem Augenblickein, wo das Ei den Mutterleib verlässt.

Um dies nachzuweisen, müssen wir zunächst dem Zellenbau der Bienen unsere Aufmerksamkeit zuwenden.

Allgemein ist die Fähigkeit der Arbeitsbiene bekannt, aus den eigenen Leibesausscheidungen, den Wachsblättchen, dreierlei Zellen herstellen zu können. Diese Zellen sind stets in von einander gesonderte Gruppen geschieden (Arbeiter- und Drohnenzellen), oder treten vereinzelt auf (Mutterzellen).

Der Uebergang von einer zur anderen Gruppe erfolgt dureh wenige, den Raum- und Lagerungsverhältnissen entsprechend ganz verschieden gestaltete, sogen. Uebergangszellen. ${ }^{2}$ ) Warum diese

1) Die Befähigung zum Eierlegen ist bei den verschiedenen Bienenindividuen auffallend verschieden. Das lässt sich festsetzen durch die Zeitdaner, welche der Hinterleib des Legethieres in der Zelle verweilt. Ich habe bei äusserlich genau gleichen Verbältnissen, namentlich unter gleicher Temperatureinwirkung, Mütter beobachtet, bei welchen diese Zeitdauer nur 2-3 Secunden währte, während andere 10, 20, 40 Secunden, ja Minuten lang nöthig hatten, um das Ei in die Zelle zu befördern. Arbeitsbienen haben stets Minuten hierzu nöthig und wechseln sehr häufig die Zellen, bevor das Ei abgegangen ist.

2) Es sei hier schon bemerkt, dass solche Uebergangszellen gar nicht selten mit Eiern besetzt werden, die jedoch von den Arbeitern meist verzehrt werden. 
strenge Gruppirung von Zellen verschiedener Beschaffenheit; worin ist überhaupt die Ursache der Entstehung von dreierlei Zellen zu suchen?

Vergeblich wird man die gesammte Literatur über die Honigbiene nach einer befriedigenden Erklärung dieser Erscheinung befragen. Wer irgend eines unserer Lehrbücher der Bienenzucht zur Hand nimmt, der wird zumeist die Angabe finden: Die bauenden Bienen hängen sich in Ketten an einander, schwitzen hierbei Wachs aus, und andere nehmen die Wachsschüppchen von den Bauchringen fort, um sie zum Zellenbau zu verwenden. Diese fast einzige Angabe ist aber nicht einmal richtig, denn die Bienen reagiren nicht auf das Wachs an sich, d. h. in der Gestalt, wie es zwischen den Hinterleibsringen austritt. Davon überzeuge man sich durch:

Versuch V.

Man belege den Boden einer zum Beobachten eingerichteten Wohnung eines bauenden Schwarmes mit schwarzem Papier, damit man die Blättchen sieht. Bald werden zahlreiche, meist wasserhelle Blättchen von oben herabfallen. Es mögen sich nun noch so viele Bienen unmittelbar über denselben hinbewegen: niemals wird man beobachten, dass dieselben solche Blättchen aufnehmen. Wenn sie in der Folge doch mit der Zeit verschwinden und zerstreut werden, so wird dies verursacht durch die relativ ausserordentlich starke Luftbewegung, welche durch die Flügelschwingungen der Bienen erzengt wird, oder durch mechanische Anstösse in Folge der Kriechbewegungen der Thiere. Niemals habe ich trotz unermüdlichster Aufmerksamkeit auch nur eine Biene den Versuch machen sehen, eines der kleinen Körperchen mit den Kiefern zu packen.

Der Mechanismus ist vielmehr folgender: Sobald Wachsblättchen an den betreffenden Stellen der Bauchringe austreten, veranlasst der hierdurch entstehende Reiz eine blitzschnell sich vollziehende Bewegung der Füsse, deren Resultat im Erscheinen der Blättchen zwischen den Kiefern besteht. Kaum sind sie dort angelangt, so werden sie in Folge eines zutretenden Secrets alsbald undurchsichtig. Ich habe unter aussergewöhnlich günstigen Beobachtungsbedingungen sogar den Austritt resp. Zutritt eines klaren Secretes direct beobachtet.

Das können aber nur diejenigen Bienen ausführen, deren Beine frei sind, die sich unmittelbar an der Baustelle befinden. Die durch Verhakung der Füsse Ketten bildenden, aneinanderhängenden 
Bienen behalten die ausgeschwitzten Blättchen solange bei sich, bis sie entweder zur Baustelle selbst gelangen, oder durch Bewegungsanstösse von aussen (kriechende Bienen u. s. w.) ihrer Bürde lerlig werden. Aus diesem Grunde nimmt denn auch das Herabfallen von Wachsblättchen in demselben Maasse $a b$, als die Baufläche an Umfang zunimmt.

Wenn aber das Wachsblättchen an sich überhaupt keine Reaction bei den Bienen bewirkt, so sind wir genöthigt, die wahre Anregung zur Bauthätigkeit in den zwischen den Kiefern zutretenden Secreten zur erblicken. Wir sind ferner zu der Annahme gezwungen: Sobald die Bienen zur Errichtung einer anderen Zellengattung schreiten, muss dem nunmehr zutretenden Secrete auch ein anderer Charakter anhaften, der nicht nur eine Qualität besitzt, die den Austritt des gleichen Secrets bei anderen Bienen veranlasst, sondern damit auch dem Mechanismus der Bauthätigkeit eine andere Gestaltung verleiht, und ferner: Da die drei Zellengattungen oft gleichzeitig an verschiedenen Stellen, aber stets in von einander gesonderten Gruppen, erbaut werden, so schliessen sich die bauenden Bienen jener Gruppe an, wo dasjenige Secret zur Verwendung kommt, welches ihrem physiologischen Zustand gemäss in ihrem Organismus zur Verwendung drängt.

Die Thiere müssen sonach durch Vermittlung ihres Geruchsorgans auf die verschiedenen Secrete, welche vermuthlich flüchtige Stoffe enthalten, in entsprechender Weise reagiren können. Andererseits muss die Zellform, wie folgender Versuch lehrt, unter normalen Umständen die Anregung zur Ausscheidung der betreffenden Secrete an die Zellwandungen anregen.

\section{Versuch VI.}

Man füge einer kleinen, gut besetzten Bienencolonie mit rüstiger Mutterbiene eine seit einem halben Jahre nicht benutzte, vorher durch Wasser auf's Gründlichste gereinigte und wieler getrocknete Wabe ein. Die nach leeren Zellen verlangende Mutterbiene wird dieselbe nebst zablreichen anderen Bienen alsbald beschreiten. Sie wird auch hier und da ein Ei absetzen, allein die Bienen fressen es wieder auf, und erst nach emsiger Thätigkeit in den Zellen bleiben die abgelegten Eier und werden zu Thieren herangebildet, wie sie der Zellenform entsprechen. Die neue Qualität, welche den Zellen durch die emsige Arbeit der Bienen. 
zugefügt wurde, stellt sich unseren Augen dar als ein glänzender Ueberzug, welcher den Zellen vorher abging. Wir Bienenwirthe nennen diese Umwandlung "Einspeicheln".

Die als flüchtig erscheinenden, hellen Substanzen sind es, welche die ersten Entwicklungserscheinungen im Ei veranlassen.

Nach Privatmittheilung Petrunkewitsch's, der die mikroskopische Untersuchung von durch mich gelieferten Eiern unternahm, standen zwanzig Minuten alte und noch ältere Eier, welche die Mutterbiene ausserhalb der Zellen fallen liess, ohne Ausnahme auf dem Stadium der ersten Richtungsspindel, während Eier, die fünfzehn Minuten lang ohne Berührung durch die Bienen in den Zellen regelrecht gelegen hatten, alle bereits vorgeschrittenere Entwicklungserscheinungen zeigten.

Ferner: Eier, die nicht regelmässig abgelegt, oder möglichst bald dem directen Einfluss der Bienen entzogen werden, entwickeln sich nie zu Larven.

Bei regelmässiger Eiablage sitzt der dem Mikropylende entgegengesetzte Pol stets derart dem Zellenboden auf, dass das Mikropylende frei in der Luft schwebt. Ueber diese auffallende Stellung der Bieneneier, welche diese Lage mit zunehmendem Alter immer mehr aufgeben, hat man bisher vergeblich geräthselt. Auch mir ist der Grund hierfür erst dann klar geworden, als ich mich veranlasst sah, zu Untersuchungszwecken Tausende von Eiern in verschiedenen Flüssigkeiten zu conserviren. Wurden hierzu klare, von der Eifarbe abweichende Flüssigkeiten gewählt, so konnte ich deutlich erkennen, von woher das Eindringen der Flüssigkeiten erfolgte. Es geschah dies von beiden Polenden, und zwar den äussersten Spitzen ber, wiewohl vom Mikropylpole aus zumeist etwas lebhafter als von dem Pole her, mit welchem das Ei aufsitzt. Liegt nun hier schon die Annahme nahe, es vollziehe sich bei regelmässiger Lage des Eies eine ihrer Natur nach unbekannte Entwicklungsanregung im Ei durch die der Zelle imprägnirte Substanz, so wird doch diese Annahme durch eine von mir und Anderen beobachtete Thatsache mehr als wahrseheinlich gemacht.

Fehlerhaft organisirte Mutterbienen legen nämlich oft die allermeisten Eier nicht regelmässig, sondern flach auf den Boden oder die Zellwände ab. Aus ihnen entwickeln sich niemals Larven, so lange sie auch in den Zellen des Brutnestes verweilen mögen. Das 
erscheint auch sehr natürlich,.. denn sie empfangen weder durch die Zelle selbst noch durch die directe Beeinflussung der Bienen vom Mikropylende her Entwicklungsanstösse, da beides in dieser Lage ausgeschlossen ist. Dass aber die von den Zellen selbst ausgehenden ersten Entwicklungsanregungen den Larvenzustand nicht herbeizuführen vermögen, beweist:

\section{Versuch VII.}

Einer gut besetzten Colonie mit wenig Wabenbau stelle man eine bereits "eingespeichelte", eierfreie Wabe ein. Findet man nach 10 bis 15 Minuten die Mutter mit Eiablage auf derselben beschäftigt, so fege man sie nebst den anhaftenden Bienen rasch $a b$, verschliesse die Wabe beiderseits mit feiner Drahtgaze, die den Bienen den directen Zugang zu den Eiern wehrt, hänge die Wabe dann wieder mitten in's Brutnest zurück und untersuche nach drei Tagen. Anstatt Larven wird man eingetrocknete Eiskelette vorfinden. Bei diesem Versuch ist es gleichoültig, ob man es mit befruchteten oder unbefruchteten Eiern zu thun hat.

Wenn dem gegenüber behauptet wurde, die Eier müssten, um sich entwickeln zu können, angefeuchtet werden, so gebe ich das recht gerne zu, bestreite aber die Richtigkeit der Annabme, als ob dieses Anfeuchten durch Wasser erfolge, denn die Eier entwickeln sich regelmässig auch dann zu Larven, wenn die Bienen wochenlang nicht nach Wasser ausfliegen können.

Die gesammten Entwicklungserscheinungen legen vielmehr den Schluss sehr nahe, dasses sich hier um eine Anfeuchtung der Fier mit denselben Stoffen handelt, welche auch die Entstehung von dreierlei Zellenformen veranlassen und die die Entwicklungsrichtung der Eier bestimmen.

Sie sind jedoch wesentlich verschieden von der milchähnlichen Nährmasse für die aus den Eiern hervorgegangenen Larven, obwohl sie derselben als Bestandtheil zugefügt werden. Dass der Larve in der That zwejerlei Substanzen zugeführt werden, davon kann man sich durch die allererste Zufuhr überzeugen. In den ersten 5 bis 15 Minuten erweist sich dieselbe als vollkommen klar. Dann tritt die undurchsichtige, milchähnliche Flüssigkeit hinzu. Nicht diese letztere, sondern die klare Flüssigkeit muss es aber sein, auf welche die Bienen in überraschender Weise reagiren, wie wir ersehen wollen aus: 


\section{Versuch VIII.}

Man entnehme einer normalen Colonie die Mutterbiene. Nach drei Tagen wird man neben hier und da entstandenen, runden Mutterzellenanfängen auch mindestens eine runde Mutterzelle über einer jungen, in irgend einer Arbeiter- oder Drohnenzelle lagernden Larve vorfinden. Man zerstöre dieselbe und entferne die Larve. Sodann hole man mit der Spitze eines feinen Malerpinsels etwas Flüssigkeit heraus und zwar dort, wo sie vorzugsweise ein klares Aussehen zeigt. Damit betupfe man in nicht allzugeringem Maasse junge Larven in Arbeiterzellen, die man sich genau merkt. Hat man die Uebertragung geschickt ausgeführt ${ }^{1}$ ), so wird man am anderen Morgen finden, dass sammtliche betupften Larven jetzt nicht mehr in Arbeiterzellen, sondern in solchen Zellen liegen, die während der Nacht zum Zwecke der Heranzucht von Mutterbienen umgeformt wurden ${ }^{2}$ ).

Offenbar der charakteristische Geruchreiz dieser übertragenen Stoffe hat nicht nur den Umbau der Arbeiterzelle zur Mutterzelle veranlasst, sondern er bewirkt auch die nunmehr normal fortschreitende Umbildung des Thieres zum echten, weiblichen Geschlechtsthier. Betupft man die Larven jedoch mit der breiartig: erscheinenden Masse, so ist der Zelleninhalt am nächsten Morgen verschwunden.

Aus diesem Versuche geht aber mit Gewissheit hervor: Die zellenformbestimmende und thierformbestimmende Substanz ist die gleiche und ist charakterisirt durch Geruchsqualitäten, welche bei den am Aufbau der Thiere betheiligten Bienen durch Vermittlung des Geruchsinnes die gleichartige Absonderung veranlasst.

Bezeichnen wir diese in dreifacher Zusammensetzung von den Arbeitsbienen producirten, klaren Flüssigkeiten als die ges chlechts bestimmenden Secrete, so wird das folgende Experiment die Berechtigung darthun, den zweiten Bestandtheil des Larvennährfutters,

1) An die Wände dürfen keine Spuren gelangen, die Arbeit darf nicht bei zu grosser Hitze geschehen, da die Flüssigkeit rasch eintrocknet; auch gelingt der Versuch oft nicht, wenn man den Futtersaft aus der larvenbesetzten Mutterzelle einer fremden Colonie entnimmt u. s. w. Jedoch liegen bezüglich der letzteren Erscheinung noch zu wenig Erfahrungen vor, als dass daraus irgendwelche Folgerung gezogen werden dürfte.

2) Die Umformungsvorgänge werden weiter unten noch näher beleuchtet. 
welchen Leuckart als eine der Milch der Säugethiere vergleichbare Drüsenabsonderung definirte ${ }^{1}$ ), zu bezeichnen mit dem Namen: volumenbestimmende Substanz.

\section{Versuch IX.}

Man nehme einer Colonie die Mutterbiene weg wie alle offene Brut mit Einschluss der Eier. Hierauf füge man eine Wabe mit Larven in Arbeitszellen ein, die, im fünften Tage des Larvenzustands, nur noch Stunden bis zur Decklung vor sich haben. Nach 24 Stunden stelle man das Ergebniss fest. Ist es den Thieren inzwischen gelungen, eine oder die andere larvenbesetzte Zelle noch vor Eintritt der Zellen-Längsachsenrotation ${ }^{2}$ ) der Larven in runde Zellen umzubauen, die sie als nunmehrige Mutterzelle bald wieder schliessen müssen, so öffne man eine derselben, entferne die Larve und stelle den Inhalt fest. Man wird nur wenig Substanz von vorzugsweise dünnflüssigem, hellerem Aussehen vorfinden. Oeffnet man die Zelle erst nach vier Tagen, so ist keine Spur von Nährsubstanz mehr zu entdecken, während man bei normaler Ernährung der Mutterbiene auch nach dem Ausschlüpfen noch einen breiartigen Uebersehuss vorfindet, der für die Regel das Eigengewicht des Thieres übertrifft.

Lässt man sich nun die Thiere in solchen Nachschaffungsmutterzellen ruhig entwickeln, so gehen aus ihnen nach allen ihren Merkmalen tadellos echte - Miniaturmutterbienen hervor. Ich habe auf dem Bienenstande des Handelsbienenzüchters Mulot dahier wiederholt solche gesehen, die sogar kleiner waren als eine normale Arbeitsbiene, während eine normal entwickelte Mutter gut das doppelte Gewicht derselben besitzt. Das durch die Arbeitsbienen noch in letzter Stunde der Arbeiterlarve zugeführte, geschlechtsbestimmende Secret hat mithin ausgereicht, die vollkommene Umwandlung der Larve zum echten, proportionalen Mutterthier zu bewirken. Die volumenbestimmende Substanz war jedoch nicht annähernd in der Menge vorhanden, wie sie als nothwendig erscheint,

1) „Bienenzeitung“, Jahrgang 1871 S. 230.

2) Eine Bewegungsänderung der Larve, die den Anstoss zum Verschliessen der Zellen abgibt, aber eine trotzdem bis dahin ausser von mir noch von niemand beobachtete wichtige Erscheinung, die den Mechanismus der Thätigkeiten in der Bienencolonie so recht deutlich illustrirt. Ich werde später darauf zurückkommen. 
um die Organe in ausreichendem Umfange aufzubauen. Dönhoff hat durch ein sehr geschickt ausgedachtes Verfahren sogar planmässig solche Miniaturmütter erzogen, indem er den Larven die volumbestimmende Substanz nur in einer nicht ausreichenden Menge zugänglich machte ${ }^{1}$ ).

Das gleiche Missverhältniss zu Ungunsten der volumbestimmenden Substanz macht sich auch sehr häufig bei Heranbildung von Arbeitsbienen und Drohnen geltend. Namentlich bei der italienischen Bienenrasse treten ausserordentlich häufig die allerliebsten Liliputer von Arbeitsbienen, oft nur in der Grösse von Stubenfliegen, auf, die, mit ihren winzigen Blüthenstaubbällchen zu Hause anlangend, stets die Heiterkeit aller Beschauer wachrufen. Lässt sich nun hier die Ursache für das vorliegende Absonderungsmissverhältniss durch die Arbeiter nicht direct nachweisen, so kann man doch indirect erweisen, dass nur mangelhafte Zufuhr an volumbestimmender Substanz die Ursache der Entstebung von Zwergbienen ist. Nimmt man nämlich jeden Tag eine larvenbesetzte Arbeiterwabe auf die Dauer von etwa 10 Stunden in zwei Zeitabschnitten bienenfrei aus der Wohuung, um sie dann wieder einzuhängen, so kann man mit Bestimmtheit auf das Erscheinen von Zwergbienen rechnen. Mangelhafte Zufuhr an volumbestimmender Substanz ist auch Ursache der Entstehung abnorm kleiner Drohnen.

Drohnen können, wie schon erörtert wurde, auch in Arbeiterzellen entstehen, deren Bodenfläche, wie bekannt, beträchtlich geringer ist als jene der Drohnenzelle. Die Absonderung der volumbestimmenden Substanz erfolgt aber Seitens der Arbeiter stets auf den Zellenboden und zwar nur solange, als das Thier die Masse ohne directe Berührung der Larve dort noch ablagern kann. Diese Bedingung ist aber in Folge des rascheren Wachsthums der Drohnenlarve etwa am Ende des vierten Tages des Larvenzustandes schon nicht mehr erfüllt, während die Drohnenlarve normaler Weise nach meinen Beobachtungen etwas über fünf Tage lang diese Zufuhr erhalten muss. Es muss daher in Folge des Missverhältnisses zwischen dem vorhandenen Raum und der Wachsthumsgeschwindigkeit der Larve dieselbe Erscheinung eintreten wie die in Versuch IX dargestellte. F. Huber hat durch Uebertragung von Larven, die sich 
in Arbeiterzellen zu Miniaturdrohnen entwickelten, normale Drohnen in Drohnenzellen erzielt ${ }^{1}$ ).

Ein Mehr oder Weniger der volumbestimmenden Substanz bewirkt hiernach keineswegs die Entstehung von Abnormitäten, sondern nur das Zustandekommen von Wesen, die entweder die Wachsthumsgrenze der Species erreichen oder hinter derselben zurückbleiben. Sie ist daher auch nach meiner Auffassung an sich für alle drei Bienenwesen im Wesentlichen von gleicher Beschaffenheit. Sehen wir doch bei verwandten Insecten, welche ihre Nachkommen durch andere Organismen ernähren, ebenfalls nur eine Zufuhr von Nährstoffen gleicher Qualität, wenn auch vielfach die Quantität für die verschiedenen Geschlechtsthiere von einander abweicht ${ }^{2}$ ). Was aber dort die futterreichenden Thiere den herbeigetragenen Larven $u$. s. w. auf gewisse, den Niststätten wie ihren Bewohnern eingeimpfte Reize hin noch weiter zufügen und von welcher Wirkung diese weitere Beigabe ist, ob nicht gerade diese Reize die abweichende Quantitätszufuhr veranlassen und regeln, das entzieht sich vorerst unserer Beurtheilung.

In der Bieneneolonie treten indessen auch sehr häufig wirkliche Missbildungen auf, die unmöglich auf mangelhafte Zufuhr der volumbestimmenden Substanzen zurückgeführt werden können, sondern nur einer regelwidrigen Zufuhr der geschlechtsbestimmenden Secrete ihre Entstehung verdanken müssen. Es sind die sog. Bienenzwitter. Sie kommen wohl alljährlich auf allen grösseren Bienenständen vor, ohne jedoch bemerkt zu werden, da nur wenige Bienenwirthe Interesse daran haben, solchen Erscheinungen besondere Aufmerksamkeit zuzuwenden. Im Jahre 1900 hatte ich besonderen Anlass, solche Bildungen zu sammeln, und brachte deren im Monat Juni nicht weniger als 120 Stück zusammen.

1) Neue Beobachtungen von $F$. Huber.

2) Es ist zwar eine nicht anzuzweifelnde Thatsache, dass den Arbeiter- und Drohnenlarven kurz vor Bedecklung der Zelle Honig und Pollen zugeführt wird, während dies unterbleibt bei Larven in Mutterzellen. Auf Grund dieser Erscheinung glaubte Le u ckart schliessen zu müssen, dass dieser Unterschied in der Nahrungsbeschaffenheit mit der Ausbildung der Geschlechtsapparate in innigster Verbindung stehe. („Bienenzeitung" 1855 S. 210.) Allein durch Versuche von v. Berlepsch und Dönh off („Bienenzeitung " 1856 S. 173) wurde mit Gewissheit erwiesen, dass hier eine secundäre Erscheinung vorliegt, die mit der geschlechtlichen Ausbildung nicht im Zusammenhang steht. 
Die Untersuchung. solcher Zwitterbienen bildete seiner Zeit den Gegenstand hervorragenden Interesses für die Bienenforscher Gerstäcker, Dönhoff, v. Siebold und Leuckart. Und wenn mir Leuckart am 1. August 1897 als Gutachten auf meine ihm vorgetragene Entwicklungstheorie der Bienen u. a. bemerkte: „In der That wäre das die einfachste und natürlichste Lösung der Schwierigkeiten, besonders jener, die uns die Insecten bereiten, denn die sog. unvollkommene Befruchtung, auf die man bisher meist zur Erklärung sich stützte, ist doch streng genommen - nur eine Umschreibung unserer Unkenntniss —", so hat er gewiss nicht an letzter Stelle an die überraschenden Untersuchungsergebnisse solcher Bildungen gedacht. Diese Untersuchungen sind für die von mir aufgestellte Behauptung: Auch die normalen Bienenmännchen gehen aus befruchteten Fiern hervor, von geradezu entscheidender Bedeutung, und ich kann mir daher. nicht versagen; etwas näher auf den Gegenstand einzugehen.

Der Erste, welcher auf Bienenzwitter aufmerksam machte, war der Bienensehriftsteller Lucas. Er stiess dabei aber auf grossen Unglauben. Erst als Dr. Dönhoff und Prof. Menzel in Zürich wieder neue Mittheilungen hierüber brachten, sahen sich auch v. Siebold und Leuckart zu eingehender Prüfung solcher Missgeburten veranlasst, und Le u ckart hielt uber seine Untersuchungsergebnisse auf der Versammlung der Aerzte und Naturforscher zu Giessen einen Vortrag, dem ich folgende Darstellungen entnehme ${ }^{1}$ ): "Was sie mit weiblichen Bienen gemein haben, theilen sie auch sonst mit der Arbeitsbiene, niemals mit der Königin; sie sind gewissermaassen als Arbeiter zu betrachten, die eine mehr oder minder grosse Menge männlicher Charaktere angenommen bahen. In der Regel überwiegt auch bei ihnen das weibliche Moment in dem Grade, dass die Beziehungen zu den Arbeitern ganz unverkennbar sind, doch gibt es auch Fälle, in denen das Umgekehrte vorkommt, so dass mankleine Drohnen mit einzelnen weiblichen Attributen vor sich zu haben glaubt. Die Vermischung der beiderlei Charaktere zeigt übrigens so mannigfache Verschiedenheiten, dass kaum jemals zwei völlig gleiche Zwitter gefunden werden. Gewöhnlich sind die weiblichen und männlichen

1) Dem Auszug entnommen in: Franz Huber, Neue Beobachtungen, deutsch mit Anmerkungen von Georg Kleine. Einbeck, Druck u. Verlag v. Ehlers. 
Attribute (vorn und hinten, rechts und links, aussen und innen) auf das bunteste Durcheinander gewürfelt.

Uebrigens gibt es keine inziges unter den die Geschlechtscharaktere bestimmenden Organen, das nicht gelegentlich den Sitz der hermaphroditischen Bildung abgäbe, doch ist es unverkennbar, dass nicht alle in gleicher Häufigkeit heimgesucht werden. Man würde jedoch irren, wenn man annähme, dass es sich bei den Zwittern immer nur entweder um männliche oder weibliche Charaktere handele. Auch Mittelformen $z$ wischen beiden, die sonst im Normalzustande nirgends angetroffen werden, sind nichts weniger als selten. Namentlich gilt solches für die Mundwerkzeuge und Hinterbeine mit ihren Körbchen und Bürsten, aber auch bei den Antennen, Augen und bei den Hartgebilden der Geschlechtsöffnung lässt sich nicht selten das Gleiche beobachten....

In noch vielen anderen Fallen fand sich ein Stachelapparat von unvollständiger Verhornung mit Lade und Borsten, die von einander getrennt und unregelmässig gebogen waren, wie das auch v. Siebold von einigen seiner $Z$ witter angibt. An diese schliessen sich sodann noch weitere drei Fälle an, in denen die eine rechte oder linke Hälfte des Stachelapparates verkümmert war, ohne dabei die weibliche Bildung völlig zu verlieren ... In einem Falle waren die Dorsalschienen des siebenten Rückensegmentes nach Drohnenart unter sich verwachsen. Dieser letzte Fall führt durch Weitergreifen der männlichen Bildung sodann zu der weitaus interessantesten Form des Hermaphroditismus, der sich in einer förmlichen Combination beiderlei Geschlechtsorgane ausspricht ... Die Bildung der inneren Geschlechtsorgane konnte an den dem Redner zu Gebote stehenden Präparaten leider nur unvollkommen untersucht werden, doch gelang es mehrmals, die Angabe v. Siebold's über die häufige Coexistenz männlicher und weiblicher (freilich immer eileerer) Genitalröhren $\mathrm{zu}$ bestätigen. Am meisten war das bei den Exemplaren mit mehr oder minder vorwaltender Hinterleibsspitze, bei denen auch die inneren Organe vorwaltend männlich waren und gewöhnlich nur eine geringe Menge vereinzelter oder gruppenweise beisammenstehender Eiröhren enthielten."

Bevor ich auf eine Deutung der Befunde an Zwitterbienen auf Grundlage meiner Theorie eingehen kann, muss ich zunächst versuchen, meine diesbezüglich gewonnenen Anschauungen in möglichst präciser, anschaulicher Gestalt wiederzugeben. 
Im reifen Bienenei an sich ist nur die Anlage zur männlichen Formbildung vorhanden, welche wir mit $m$ bezeichnen wollen. Erst durch Spermazufuhr in's Ei wird die Anlage zur weiblichen Formbildung zugeführt, welche mit $w$ bezeichnet werden mag. Beide formbildenden Bestandtheile treten bei den drei Thierformen in drei verschiedenen Wachsthums- und Austauschverhältnissen in Function. Zur Regulirung dieser Wachsthumsrichtungen werden durch die Mundtheile der Arbeiter dreierlei, den Wachsthumsrichtungen conforme Drüsensecrete abgesondert, die auch Ursache der Entstehung von dreierlei Zellenformen sind.

Das Secret zur Heranbildung des Männchens sei mit $a$ bezeichnet. Es hat die Eigenschaft, die Formbildung $m$ in dem gleichen Maasse zu fördern, als es die EntwickJung der Formbildung $w$ behindert. Das Secret zur Aufzucht des Weibchens möge $b$ genannt sein. Durch seine Einwirkung wird Formbildung $w$ zum Nachtheile von $a$ im Wachsthum gefördert.

Das Secret für Heranzucht von Arbeitern bleibe vorerst unbezeichnet.

Ohne diese Annahme der Existenz von Säften genannter Beschaffenheit würde bei gleicher Vererbungsenergie der Elternthiere nach meiner Vorstellungsweise die Entstehung von ausgesprochenen Geschlechtsthieren ausgeschlossen sein, es würden nur hermaphrodite Formen zur Ausbildung gelangen.

Da aber $a$ wie $b$ an den Organismus der Arbeiter gebunden sind, so bilden sie das Supplement $z u$ den einseitig entwickelten Geschlechtsleistungen der begatteten Mutterbiene. Die Arbeitsbienen können sonach auch nur als Geschlechtsthiere, wenn auch besonderer Art, aufgefasst werden, und sie sind dies um so mebr, als sie auch die volumbestimmenden Substanzen für die Embryonen ausschliesslich produciren, die mit $c$ bezeichnet werden mögen. Die begattete Mutterbiene dürfte hiernach als grundlegendes, die Arbeitsbiene als bestimmendes Geschlechtsthier bezeichnet werden.

Die Productionsstätten $a, b, c$ sind unter jenen Drüsen der Arbeitsbienen zu suchen, welche bei den Geschlechtsthieren der Honigbiene nur schwach oder gar nicht functioniren, möglicher Weise aber auch bei der Mutterbiene zum Theil andere Functionen übernommen haben.

Die Reize zur Ausscheidung von $a$ oder $b$ unterstehen unter normalen Verhältnissen der Regulation durch die Geruchsorgane 
und werden, den physiologischen Zuständen der Thiere gemäss, ausgelöst durch die in die Mundtheile gelangenden Wachsblättchen, wie, durch die in den Zellen abgelegten Eier. Der Austritt von $c$ erfolgt durch Bewegungsreize der Mundtheile Seitens der Mutterbiene wie der Arbeitsbiene selbst, und vor Allem durch Bewegungsreize der in den Zellen lagernden Larven. An die Larve wird aber nicht nur $c$, sondern gleichzeitig auch noch $a$ ausgeschieden, wenn das Männchen, und $b$ abgesondert, wenn das Weibchen herangebildet wird. Die Ergebnisse meiner Versuche machen ferner die Annahme wahrseheinlich, dass bei Zellenbau, Ei- und Larvenpflege zur Heranbildung von Arbeitsbienen die Secrete $a, b$ gleichzeitig in einem constanten Mischungsverhältniss abgesondert werden.

Vergleichen wir nun dieses Schema mit der heute in maassgebenden zoologischen Kreisen vertretenen Auffassung, wonach die Entstehung der Geschlechtseigenthümlichkeiten von den jeweiligen Zuständen des Geschlechtsapparates abhängig ist, so weist dasselhe, streng genommen, eine principielle Abweichung von dieser Anuahme gar nicht auf. Der Unterschied ist vielmehr nur ein individueller, und zwar dergestalt, dass diese jeweiligen Zustände des Geschlechtsapparates in der Bienencolonie in besonderen Thierformen, den Arbeitsbienen, verkörpert sind. Die nachfolgenden Darlegungen werden, wie ich hoffe, diese allgemeine Bemerkung mehr und mehr bestätigen.

Diese Anschauungsweise setzt aber in erster Linie das Befruchtetsein aller Eier voraus, da nur aus ihnen die dreierlei Normalthiere hervorgehen können, denn ohne Erfüllung dieser Voraussetzung wäre nur die Entwicklungsfähigkeit nach einer Richtung hin möglich. So muss es denn auch, nach allen meinen Versuchen, in Wirklichkeit sein. Unbefruchtete Eier entwickeln sich, wie schon seit mehr als einem Menschenalter u $\mathrm{n} z$ w e i fe lb a f t feststeht, nicht nur in Drohnen-, sondern auch in Arbeiterzellen, stets nur zu ausgesprochenen männlichen Formen.

Aus dieser Thatsache müssen wir aber folgern: Im reifen Bienenei an sich sind nur die Anlagen zur männlichen Formbildung vorhanden; und auf der Hand liegt damit die zweite Annahme: Erst durch das Sperma wird die Anlage zur weiblichen Formbildung, wie zur Entstehung von Arbeitern, dem Ei zugeführt. Diese letztere Behauptung bedarf des Beweises.

Zum Verständniss derselben muss ich mit Rücksicht auf die nach- 
folgend angewendete Bezeichnung: echte Mutterzelle, im Gegensatz zu: Nachschaffungszelle, vorausgehend eine Erörterung geben.

Die echte Mutterzelle hat in ihrer ursprünglichen Anlage die Halbkugelgestalt, ähnlich dem Eichelnäpfchen, aus dem die Eichel herausgefallen ist. Das in sie abgelegte $\mathrm{Ei}$ erfährt von dem Augenblick der Ablage ausschliesslich nur diejenige Beeinflussung, welche zur Heranbildung des Mutterthieres hinführt. Die Nachschaffungszelle ist nun zwar auch eine Zelle, aus welcher das Mutterthier hervorgehen kann und immer hervorgehen soll; sie entwickelt sich im ${ }^{-}$ weiteren Wachsthum auch der echten Mutterzelle entsprechend, allein die Grundlage derselben ist entweder eine larvenbesetzte Arbeiteroder Drohnenzelle. Ueber einem Ei wird niemals eine Mutterzelle errichtet.

Die Aulage der Nachschaffungszelle gestaltet sich ganz nach dem Zelleninhalt. Ist die innenliegende Larve noch sehr klein, dann werden die sechs Zellenwände stark abgetragen, und die runde Form der Mutterzelle nimmt lierauf die Stelle derselben ein. Nur dem genauen Kenner ist es in solcher Fällen möglich, zu constatiren, ob es sich im vorliegenden Falle um eine echte Mutterzelle oder um eine Nachschaffungszelle handelt. Einen wichtigen Anhaltspunkt bildet der in bei Weitem den meisten Fällen dreiseitig pyramidal angelegte Zellenboden der Arbeiter- und Drohnenzelle. Was bei Anlage einer Nachschaffungszelle hindert, das wird von den Bienen abgetragen.

Zum weiteren Verständniss der nun folgenden, meines Dafürhaltens äusserst wichtigen Entdeckung, die lediglich einer logischen Erwägung ihre Existenz verdankt, sei nochmals erinnert, dass die Entstehung von Lebewesen männlicher Formbildung aus un befruchteten Bieneneiern in Arbeiter- oder Drohnenzellen, (mögen dieselben nun herrühren von der begattungsunfähigen Arbeiterin oder der unbegatteten Mutterbiene), eine durch die gesammte Erfahrung absolut feststehende Thatsache ist.

Da mir nun schon vor Jahren die verschiedenen Zellenformen als verkörperte Ausdrücke der Geschlechtsfunctionen der Arbeiter erschienen, so musste sich mir die weitere Erwägung aufdrängen: Verursachen dieselben Substanzen, welche die Entstehung der Mutterbiene veranlassen, auch gleichzeitig die Entstehung der betreffenden Zellenform (im vorliegenden Falle die Entstehung der echten Mutterzelle), so kann in dieser Zelle unmöglich aus dem unbefruchteten Ei ein Lebewesen hervorgehen, da die von vornherein derselben im- 
prägnirte und in der Folge dem Ei zugeführte Bestimmungssubstanz zwar das Wachsthum der vorhandenen männlichen Anlage im Ei unterdrücken, nicht aber auch gleichzeitig das Heranwachsen eines Weibchens fördern kann, eben weil dem unbefruchteten $\mathrm{Ei}$ die Anlage für Bildung eines solchen nicht zugeführt wurde.

Schon seit vielen Jahren habe ich zwecks Feststellung der Richtigkeit dieser Erwägung die grössten Opfer nicht gescheut. Mindestens 14 Colonien wurden absichtlich in tlie Zustände versetzt, unter welchen nur unbefruchtete Eier zur Bebrütung in jene echten Zellen gelangen können. Ebenso habe ich wiederholt andere Bienenstände, auf welchen sich die gleichen Fälle unbeabsichtigt, in Folge von Störungszuständen des Normalverlaufs, eingestellt hatter, zur Feststellung der Ergebnisse aufgesucht.

Ueberall wurde die Richtigkeit des Schlusses bestätigt ${ }^{1}$ )! Schon beim dritten Falle wäre ich indessen fast zweifelhaft geworden, hätte ich nicht die vorliegende Erscheinung einer sorgfältigen Prüfung unterzogen. Am vierten Tage nach Besetzung einer echten Mutterzelle mit einem unbefruchteten $\mathrm{Ei}$ zeigte sich nämlich, scheinbar an derselben Stelle; eine runde Zelle, besetzt mit einer ganz jungen Larve, und im ersten Augenblick musste ich annehmen, das unbefruchtete $\mathrm{Ei}$ sei dennoch in der echten Mutterzelle zur Larve geworden. Die genaue Untersuchung aber ergab, dass die Larve in einer un echten, einer Nachschaffungszelle lag. In einer unmittelbar neben der echten Mutterzelle gelegenen Drohnenzelle war, wie auch in andern Drohnenzellen, eine junge Larve ausgegangen. Hierüber errichteten die Thiere in dem Triebe, die fehlenden Mutterthiere wieder zu ersetzen, alsbald eine Nachschaffungszelle, und dabei wurde zu Gunsten derselben die echte Mutterzelle nebst Ei vernichtet, weil sie hindernd im Wege stand. Diese Erscheinung kam mir wiederholt vor, andert aber nichts an der Thatsache: A us unbefruchteten Bieneneiern geht auch unter den sonst günstigsten Bedingungen dann kein Lebewesen hervor, wenn es in die echte Mutterzelle abgesetzt und daher von vornherein durch die Arbeitsbienen auf Heranbildung des Weibchens beinflusst wird. Die Anlage

1) Wie ich später in alten Jahrgängen der „Bienenzeitung" entdeckt habe, hat auch schon Dönhoff die Thatsache wiederholt festgestellt, dass sich aus a nbefruchteten, in echte Mutterzellen abgesetzten Eiern, niemals Lebewesen entwickeln. 
zur weiblichen Formbildung ist soweit an das Sperma gebunden.

Zum Beweise dafür, dass auch aus dem unbefruchteten Ei niemals in der Drohnenzelle ein Bienenweibchen oder eine Arbeitsbiene entstehen kann, führe man aus:

Versuch $\mathrm{X}$.

Eine Colonie mit einer eierlegenden Mutterbiene, deren Begattung man absichtlich verhindert hat, fege man ab auf lauter Drohnenwaben. Man führe dies gegen Abend aus nnd reiche der Colonie während der Nacht eine tüchtige Portion Honig oder Zuckerlösung, damit sich die Bienen durch das Auftragen des Futters mit den ungewohnten Verhältnissen während der Nacht aussöhnen.

Die Mutterbiene wird bald Eier in die Zellen absetzen, die Arbeiter zehren dieselben jedoch immer wieder anf. Nach einigen Tagen, während welchen die Arbeiter die Zellen eifrig bearbeitet haben, auf Heranbildung von Arbeitsbienen, bleiben die Eier und werden bebrütet. Es entstehen jedoch in allen Fällen auschliesslich nur normalgrosse Thiere von männlicher Gestalt, niemals aber Arbeitsbienen, und niemals habe ich irgendwelche Störungserscheinungen im Entwicklungsverlauf beobachtet.

So zwecklos dieser Versuch auch erscheinen mag, so bedeutungsvoll ist er doch einmal als Widerlegungsbeweis für die Behauptung meiner Gegner, die Bienen seien fähig, befruchtete von unbefruchteten Eiern unterseheiden zu können. Anfangs fressen die Bienen die Eier auf, weil sie, ihrem physiologischen Zustand entsprechend, andere Reize nothwendig haben, als sie ausgelöst werden durch Eier in Drohnenzellen. Nachdem sie die Zellen jedoch umgespeichelt haben zur Heranbildung von Arbeitsbienen, werden genau dieselben Eier Naraufhin gepflegt, und trotzdem entstehen solche nicht, weil die Eier in Folge ausgebliebener Befruchtung zur Heranbildung derselben ungeeignet sind. Das Ei an sich ist es also nicht, wodurch das Verhalten der Bienen demselben gegenüber geregelt wird, sondern es entscheiden hierüber ausschliesslich die von den Zellen ausgehenden Reize, welche ihnen durch die Bienen selbst, ihrem physiologischen Zustand entsprechend, imprägnirt werden. Die M utterbiene reagirt jedoch nicht auf specifische Zellenreize, sonst würde sienicht in ungeeignete Zellen Eier absetzen, welche die Bienen wieder verzehren. 
Der Versuch $\mathrm{X}$ ist aber auch desshalb von grösster Wichtigkeit, weil aus später darzustellenden Störungserscheinungen der unabweisbare Schluss gezogen werden muss, dass die von der begatteten Mutterbiene unter normalen Zuständen in Drohnenzellen abgesetzten Eier ein Element enthalten müssen, welches unbefruchtete Eier nicht enthalten.

Wenn ich nun nochmals den Verlauf der Eientwicklung in der normal gestalteten Bienencolonie kurz zusammenfasse, so gestaltet sich derselbe folgendermaassen: Das Geschlechtsthier $w$ entsteht, wenn das befruchtete Ei in die mit Secret $b$ imprägnirte Zelle eingebettet wird, das Geschlechtsthier $m$ dann, wenn es in der Zelle abgelegt ist, die mit Secret $a$ imprägnirt ist, die Arbeitsbiene aber, wenn es in einer vermuthlich mit beiden Secreten in unbekanntem Mischungsverhältniss imprägnirten Zelle weiter gepflegt wird. $\mathrm{Zu}$ letzterer Annahme sind wir deshalb vorerst berechtigt, weil auch in regulären Arbeiterzellen ausgesprochene männliche Formen aus unbefruchteten Eiern hervorgehen, obwohl sie auf Arbeiter hin gepflegt werden. Es scheint dem Bestimmungssecrete für Arbeiter hiernach ein gewisser Procentsatz der männlich bestimmenden Substanz eigen zu sein.

Hiermit komme ich wieder auf die Zwitterbildungen zurück.

Die Ursache dieser merkwürdigen Hermaphrodisie glaubte v. Siebold in einer unvollkommenen Befruchtung erblicken zu müssen, die durch Zufuhr einer unzureichenden Menge von Samen bedingt sei. Leuckart widerlegte ihn jedoch mit seinen ejgenen Untersuchungsergebnissen $\nabla \circ n$ Bieneneiern, die bäufig nur einen einzigen Samenfaden enthalten hatten.

Le u ck a rt selbst glaubte den Grund in einer Abnormität jener Drüsensäfte erblicken zu müssen, die dem Inhalt der Samenblase beigemischt werde. Kleine widerlegte ihn jedoch alsbald durch die Erwägung, dass sich dann ja alle Eier zu Missbildungen in Bienenzellen entwickeln müssten, während doch die Zahl derselben, der grossen Masse von regulären Arbeitsbienen gegenüber, nur verschwindend gering sei.

Kleine selbst stellte eine Erklärung auf, welche nach heutiger Kenntniss der Befruchtungsvorgänge erst recht verfehlt ist. Er meinte, die zwitterergebenden Eier würden auf irgendwelche Weise am "rechtzeitigen Austritt" aus dem „Eingange" 1) gehindert, so dass

1) Soll wohl heissen "Eigange". 
die Entwicklung des Embryo in ihnen bereits in das erste Stadium eingetreten sei, ehe es das Sperma aufnehme.

Es ist aber nichts natürlicher als die vergebliche Bemühung dieser scharf denkenden Männer um Auffindung einer befriedigenden, naturgemässen Erklärung des vorliegenden Phänomens. Mussten sie doch, weil sie Dzierzon's Behauptung selbst bestätigt zu haben glaubten, die Mutterbiene für alles verantwortlich machen, wie ja dies heute noch geschieht, indem man ihr auf der einen Seite die Fähigkeit abspricht, in der Jugend Eier ablegen zu können, aus welchen sich Drohnen entwickeln könnten, auf der anderen Seite sie aber dreist beschuldigt, nach Willkür entweder befruchtete oder unbefruchtete Eier zu produciren.

Besehen wir uns die Sache von meinem Standpunkte aus, so steht vor allem zweifellos fest, dass die Eier für alle Missbildungen ohne Ausnahme befruchtet sein müssen. So viel Hunderte, ja, Tausende von falschen Drohnen ich auch schon aus unbefruchteten Eiern in Arbeiterzellen heranbilden liess: niemals entstanden aus denselben Formen, die auch nur eine der von Leuckart aufgezählten, fast unübersehbaren Abweichungen vom Bau der Drohnenform aufgewiesen hätte, obschon in solchen Fällen stets die Zufuhr zur Heranbildung von Arbeitsbienen durch ibres Gleichen erfolgt.

Als befruchtet müssen die den Missbildungen zu Grunde liegenden Eier bekanntlich die gleiche Vererbungsenergie der beiden Elternthiere besitzen. Würden sie daher normal beeinflusst durch die Arbeiter, so würden sie ebensowohl Männchen wie Weibchen und Arbeitsbienen ergeben haben können. Hiermit ist auch im Princip ohne. Weiteres die Möglichkeit der Entstehung von Missbildungen gegeben, die alle möglichen Uebergangsformen, wie Combinationen männlicher Charaktere mit jenen der Arbeitsbiene, aufweisen können.

Wir brauchen uns z. B. unter den fütternden Thieren nur einzelne vorzustellen, bei welchen in Folge kleiner organischer Fehler die geschlechtsbestimmenden Drüsen der Secrete $a, b$ nicht in constanten Mischungsverhältnissen functioniren, und es werden schon Reihen von Abweihungen normaler Bildungen erfolgen. Denken wir uns ferner Individuen, welche zwar auf den Geruchsreiz der Arbeiterzellen und einliegenden Futtersäfte reagiren, bei welchen aber nur die männlich geschlechtsbestimmenden Drüsen regelrecht oder überhaupt nur functioniren. Wenn ihre abnormen Absonderungen regel- 
recht den normalen zugeführt werden, so lässt sich kaum annehmen, dass die Bienen aus dem hierdurch entstehenden Gesammtgeruchscharakter" den Ueberschuss des jetzt vorhandenen, männlich bestimmenden Secretes wahrnehmen sollten, um hierauf durch Aufzehren der Futtermasse nebst Larve zu reagiren. Alle Bedingungen sind aber dann gegeben zum Entstehen von Missbildungen jeglicher Art.

Sollte indessen meine Vermuthung irrig sein, die mich vorerst das Bestimmungssecret für Arbeiter in dem gemeinsamen Austritt der Secrete $a+b$ in unbekanntem Procentsatz erblicken lässt, und es functionirte hierfür eine besondere Drüse, so würde damit die Erklärung der Zwitterbienen auch nicht im Mindesten erschwert.

Lassen sich hiernach auf Grund meiner Theorie die durch Le uckart und v. Siebold untersuchten Missbildungen durchaus naturgemäss und ungesucht erklären, so beweisen diese Missbildungen selbst aber auch direct, dass die Dzierzon'sche Theorie der Geschlechtsbildung bei den Bienen falsch sein muss. Nach dieser Lehre können aus befruchteten Eiern normaler Weise entweder nur Arbeiter oder, in höchster Vollendung, Mutterbienen entstehen. Missbildungen könnten sich daher nur in Vermischung der Charaktere von Mutter- und Arbeitsbienen äussern. Da dies aber bei allen hier in Betracht kommenden Missbildungen nicht zutreffend ist, so kann auch Dzierzon's Lehre nicht richtig sein. Umgekehrt beweist das hier nur in Betracht kommende Auftreten buntester Mischung und Verschmelzung von Charakteren der Arbeitsbienen und der Drohnen die Richtigkeit der Voraussetzung meiner Theorie, die da lautet: Die normalen Drohneneier sind auch befruchtet! Missbildungen, wie sie nach Dzierzon's Theorie nur möglich wären, kommen indessen auch in der Bienencolonie vor.

Aus Arbeiterzellen gehen bei der ägyptischen Bienenrasse, sogar constant, auch Wesen hervor, die weder Arbeiter noch Weibchen sind. Sie theilen mit der Arbeitsbiene die Grösse und die Färbung, welche wesentlich von jener des Weibchens abweicht. Auch fehlt ihnen, gleich den Arbeitern, der Begattungstrieb. In aIlen übrigen Merkmalen schliessen sie sich nach Untersuchungen von Gerstäcker, v. Siebold und Leuckart bis auf eine geringe Zahl von Eierröhren den Mutterbienen an ${ }^{1}$ ).

Ich habe wiederholt von: physiologischen Zuständen der Bienen

1) „Die Biene“, von Baron August v. Berlepsch. Zweite Aufl. S. 29. 
gesprochen, ohne bis jetzt erklärt zu haben, was ich darunter verstehe. Diese Versäumniss will ich nun gut machen, da ohne eine eutsprechende Erklärung die nun folgenden Versuche nicht wohl verständlich sind.

Es kann sich dabei an dieser Stelle selbstredend nur um Zustände und Lebensäusserungen der Biene handeln, die in directer Verbindung mit deren Geschlechtsleben stehen. Im Zellenbau einer Bienencolonie tritt uns gewissermaassen ein greifbarer Ausdruck der Geschlechtsregungen vorausgegangener Generationen entgegen, wenn wir die vorhandenen Wabenbestände zu jenem Zeitpunkt beurtheilen, wo die Reproduction der Bewohner für die Regel gänzlich ruht: zur Zeit der Wintersonnenwende. Die Urheber derselben erlebten zumeist, ja, höchstwahrscheinlich ohne Ausnahme, den Winter nicht, und den Insassen stehen bei Wiedererwachen der Fortpflanzungsthätigkeit als Hinterlassenschaft kleine, sechseckige Zellen in überwiegender, und grosse sechseckige Zellen in der Minderzahl zur Verfügung. Beide verdanken ihre Existenz zwei verschiedenen physiologischen Erregungszuständen, die wir bereits kennen lernten. Eine andere Frage ist jedoch die: Treten diese Zustände gleichzeitig neben einander auf oder stehen sie zu einander im Abhängigkeitsverhältniss? Das Verhalten der Biene lehrt es uns. Sie nehmen nicht gleichzeitig beide Zellengattungen zur Brutpflege in Beschlag, sondern im zeitigen Frühjahr stets nur die kleine Sorte. Werden zu dieser Zeit einer mässig starken Colonie Drohnenzellen selbst mitten in's Brutnest zugefügt: sie reagiren nicht darauf. Legt die Mutterbiene dennoch (wie ich das unzählige Mal beobachtet habe) Eier in dieselben $a b$, so zehren sie die Arbeiter bald wieder auf. Nur ganz ausnahmsweise entstehen in solchen Fällen auch schon im zeitigen Frühjabr wenige Drohnen; wodureh die Regel jedoch nicht alterirt wird ${ }^{1}$ ).

1) Bei Beurtheilung der Erscheinungen in der Bienencolonie darf man niemals die Thatsache aus dem Auge verlieren, dass man es hier mit einer Vergesellschaftung von Thieren zu thun hat, die zwar geschlechtlich einseitig entwickelt und gerade desshalb zum Verband gezwungen sind, bei dessen Einzelwesen jedoch der physiologische Zustand vom Gesammtnormalzustand nichtsdestoweniger schon mehr oder weniger desshalb abweichen kann, weil jedes Thier auch eine Individualentwicklung durchlebt. Nur von diesem Gesichtspunkte aus sind ganze Reihen von Erscheinungen im Bienenleben verständlich. So reagiren z. B. die Insassen derselben Colonie oft ganz verschieden auf ein Mutterthier, das man ìnen zugeben will. Gar oft sieht man in den Drohnenzellen Larven Iagern, die 
Die Erfahrung lehrt weiter, dass jede normale Colonie in erster Zeit stets nur Arbeiterzellenbau errichtet, in welchem die Bienen ihres Gleichen heranbilden.

Wir haben demnach in der Abscheidung der gemischten Bestimmungssecrete für Arbeiter und deren Zellenform den physiologischen Normalzustand einer Bienencolonie vor uns, und ihm gegenuber sind alle weiter eintretenden Entwicklungserscheinungen als mehr oder minder grosse Störungsvorgänge des Normalzustandes aufzufassen. Die Arbeiter suchen sie auszugleichen nach Massgabe der hierdurch angeregten Triebe und der ihnen zur Verwirklichung zu Gebote stehenden Hülfsmittel. Nur in diesem Sinne kann das Schwärmen als natürlicher Fortpflanzungsact der Bienen betrachtet werden, nicht in dem anderen, als $a b$ elne gewisse Individuenzahl die Theilung der Colonie bedinge.

Das beweist die gesammte Bienenpraxis. Man kann kleine Bienencolonien ohne störende Eingriffe in's Innere lediglich dadurch zum Schwärmen zwingen, dass man die Störungsbedingungen des Normalzustandes in geeigneter Weise fördert, und bei Feuersbrünsten, welche auch Bienenstände in Mitleidenschaft zogen, hat man neben Colonien, die den Flammen zum Opfer fielen, wiederholt auch solche Fälle erlebt, in welchen die Insassen dadurch gerettet wurden, dass sie als regelrechte Schwärme die Wohnungen verliessen, obwohl sie keine Spur von Vorbereitungen zum Schwärmen getroffen hatten. Dönhoff hat sehr häufig die Bienen zum Schwärmen dadurch commandirt, dass er stinkendes Thieröl in eine der Waben eingoss. Nach kurzer Zeit verliess die ganze Gesellschaft die Wohnung in Gestalt eines regelrechten Schwarmes ${ }^{1}$ ).

Wie man kleine Colonien durch Förderung der Störungsursachen zum Schwärmen zwingen kann, so können umgekehrt die mächtigsten Colonien mit einer zehn- und zwanzigfachen Individuenzahl am Schwärmen verhindert werden, wenn man die Störungsursachen des Normalzustandes fern zu halten versteht.

Als wichtigste solcher Störungsursachen sind nach meinen Erfabrungen zu bezeichnen: Mangel an Gelegenheit für die

ohne jede Aenderung äusserer Einflüsse am folgenden Tag wieder verschwunden sind. Aus dem gleichen Grunde verjagen die älteren Bienen nach Ueberschreitung des Entwicklungshöhepunktes sehr häufig die Drohnen, während die jüngeren Thiere in Heranzucht solcher ruhig fortfahren u. s. w.

1) „Bienenzeitung" 1858 und 1859. 
Arbeiter, ihre geschlechtsbestimmenden Producte in der Gestalt abzusetzen, wie es derbezeichnete Normalzustand verlangt, und anbaltende Einwirkung von Wärmegraden, welche die Grenze der Normalblutwärme') der Bienen nach oben zu überschreiten droht. Hiermit geht in der Regel eine mangelhafte Zufuhr genügend sanerstofthaltiger 'Luft Hand in Hand.

Eine der wirksamsten Störungen des Normalzustands, welche regelmässig eine Erhöhung der Stockwärme im Gefolge hat, besteht in Entfernung der Mutterbiene aus der Colonie. Welche Erscheinungen eine solche Vornahme nach sich führt, darüber werden wir Näheres erfahren durch den Verlauf des nun folgenden Versuchs, namentlich in seiner zweiten Hälfte.

\section{Versuch XI.}

Eine normale Colonie mit junger ${ }^{2}$ ) Mutterbiene, die vor wenigen Tagen erst begattet wurde, fege man zu Anfang August gegen Abend auf lauter leeren Drohnenzellenbau ab. Sodann reiche man ihr eine tuchtige Portion Honig zum Auftragen über Nacht, damit sich die Thiere durch dieses Geschäft mit der ungewohnten Lage vertraut machen. (Trotz dieser Vorsicht kommt es dennoch mitunter vor, dass die Thiere am nächsten Tage als regelrechter

1) Wie ich vermuthe, wird man den Ausdruck: Blutwärme, anstatt: "Stöckewärme", beanstanden. Desshalb muss ich folgende Versuchsreihen hier darstellen: In diesem, wie auch im vorausgehenden Winter habe ich bei einer Aussentemperatur von etwa $0^{\circ}$ verschiedentlich meinen Colonien Bienen entnommen und dieselben auf ein im Freien liegendes Brett abgekehrt. Die abfliegenden Thiere erstarren dann sofort, die nichtabfliegenden streben nach allen Richtungen aus einander, werden aber bald unfähig zum Abfliegen. In diesem Zustande habe ich sie dann möglichst auf ein Häufchen zusammengekehrt, und nach Bienenart krallten sie sich dann an einander. Nachdem sie ruhig an einander gedrängt verharrten, fübrte ich die Quecksilbersäule eines Normalthermometers in den Ballen ein. Das kleinste Häufchen Bienen mochte gegen 50 Stück zählen. Ich traute meinen Augen kaum, als ich die Quecksilhersäule von $0^{\circ}$ auf $+26^{\circ}$ steigen sah. Auf diesem Stande verharrte sie, solange der Versuch währte. Nahm ich drei und vier Mal soviele Bienen zum Versuch heran, so wurden +31 bis $32^{\circ} \mathrm{C}$. erzielt. Dieses Ergebniss halte ich für den Ausdruck der Bienen-Blutwärme. Wenn man die Fehlerquellen des Versuchs in Rechnung zieht, so dürfte es nicht als gewagt erscheinen, die Blutwärme der Bienen mit jener der Säugethiere zu vergleichen. (Nähere Angaben der Versuche: "Tllustrirte Bienenzeitung“. 1902.)

2) Ich betone ausdrücklich: junge Mutterbiene; denn wie meine Gegner behaupten, kann ja dieselbe keine Eier legen, aus welchen Drohnen entstehen. 
Schwarm ausziehen. Ohne dieselbe ziehen sie sogar meistens aus; ein erneuter Beweis für die Richtigkeit meiner Auffassung der Schwärme als Störungserscheinungen des Normalzustandes.) Bleibt die Colonie, so ist nunmehr folgendes Verhältniss hergestellt: Eine Colonie, welche lediglich auf Befriedigung des physiologischen Normalzustandes hindrängt ${ }^{1}$ ), steht gegenüber einem erstarrten Ausdruck geschlechtlicher Regungen zur Erzeugung männlicher Thiere, den es als Niststätte für Arbeitsbienen nicht umgehen kann. Nach Dzierzon's Theorie müssten nun in dieser Lage der Colonie entweder überhaupt keine Nachkommen entstehen, weil die Mutterbiene den Zeitpunkt nicht mehr für geeignet hält, jetzt noch Drohnen auf die Welt zu setzen und daher keine Eier in die Zellen hineinlegt, oder es müssten Drohnen entstehen, wenn diese sich dennoch entschliesst, Eier in diese Zellen abzulegen. Die Sache verläuft aber ganz anders. Man wird schon am nächsten Morgen hier und da abgelegte Eier wahrnehmen. Sieht man jedoch einige Stunden später nach, so sind sie an den Stellen wieder verschwunden und an anderen Stellen zeigen sich solche.

Wir ersehen hieraus: Das Mutterthier folgt innerhalb des warmen Brutnestes lediglich seinem Legetrieb, wenn nur die Eier in Zellen hinein gelangen. Die Arbeiter aber können keine Eier an solchen Stellen brauchen, wo noch nicht der ihrem physiologischen Zustande entsprechende Boden zur Aufnahme solcher geschaffen ist.

Da normaler Weise die Zellenform in Einklang mit der Thierform stehen muss, so versuchen die Bienen zunächst die Umgestaltung der Drohnenzellen in Arbeiterzellen. Das gelingt ihnen aber nicht. Hier und da bringen sie höchstens kleine Verengungen am Innenrande des Zellenausgangs zu Stande. Während dieser vergeblichen Versuche sondern aber, dem physiologischen Zustand entsprechend, ganz unwillkürlich Drüse $a+b$ im constanten Mischungsverhältniss ihre Secrete ab, und damit ist die Vorbedingung zur Entstehung von Arbeitern gegeben: Die Drohnenzellen sind in Pseudoarbeiterzellen umgewandelt worden: Die abgelegten Eier werden nun nicht mehr aufgefressen, sondern weitergepflegt und entwickeln sich zu Arbeitsbienen.

1) Erfahrungsgemäss werden namentlich bei kleineren Colonien mit junger, begatteter Mutterbiene um diese Zeit keine Drohnen mehr herangebildet, insbesonders dann, wenn sie in solchen Fällen die Brutpflege erst von Neuem wieder aufnehmen muss. 
Ich hebe hier, wie schon vorausgehend, nochmals hervor: Die Eiablage des Mutterthiers kann ganz unmöglich durch specifische, physiologische Reizeindrücke geregelt werden, die von den Zellen ausgehen und die Entwickelungsrichtung der Eier bestimmen, denn sonst würde das Thier nicht Eier ablegen, die von den Arbeitern wieder aufgefressen werden. Verhält es sich doch hier genau ebenso, wie wir das nach Versuch X auch bei der unbegatteten Mutter wahrgenommen haben. Setzt man eine starke Colonie schon früher auf lauter Drohnenzellenbau, so wird ein Theil der Zellen nicht umgewandelt, und in buntem Durcheinander entstehen Arbeiter und Drohnen gleichzeitig. Unter den hier gegebenen Bedingungen aber habe ich in den drei ausgeführten Fällen nur beim ersten neben lauter Arbeitern auch zwei Drohnen entstehen seben.

Schreiten wir nun zum zweiten Theil des Versuchs und entfernen die Mutterbiene dann, wenn in unserer Colonie viele Eier und Larven vorhanden sind. Es entsteht eine grosse Erregung und in Folge hiervon bedeutende Temperaturerhöhung. Lassen wir aber die Colonie gewähren und stellen nach zehn Tagen den Befund im Brutnest fest, so finden wir neben der weit überwiegenden Zahl flachgedeckelter Zellen, welche Arbeitsbienen enthalten, a) mehrere herabhängende, eichelförmige Zellen, die Mutterbienen enthalten, und b) noch weit mehr hochgewölbte Zellen, die Drohnen einschliessen. Bei meinem letzten Versuch dieser Art habe ich sogar 241 Stück Drohnen gezählt. Dieser Versuch ist auch von Heck ausgeführt worden mit im Ganzen gleichem Erfolg und zwar mindestens sechsmal ${ }^{1}$ ).

Es wird uns aber durch diese Ergebnisse bewiesen:

1. Durch den Verlust der Mutterbiene wird der Trieb nach Erzeugung der beiden Geschlechtsthiere bei den Bienen rege, und die Thieresind thatsächlich fähig, auch Männchen in grosser Anzahl dann heranzubilden, wenn ihnen Arbeiterlarven und Eier gleicher Entwicklungsrichtung in Drohnenzellen zu Gebote stehen.

2. Die Embryonen für Arbeitsbienen müssen bis zu einer gewissen Entwicklungshöhe geschlechtlich

1) „Bienenzeitung" 1898 und „Hessische Biene ${ }^{\prime} 1902$. 
nach beiden Richtungen hin entwicklungsfähig, also noch neutral sein.

Den Beweis hierfür habe ich, mit Mulot in Gemeinschaft, auch direct erbracht. Aus einem Stückchen Drohnenwabe aus einem Normalstock, das mit jungen Larven besetzt war, entfernten wir alle vorhandenen Larven, und untersuchten wiederholt, ob wir auch keine übersehen hatten. Hiernach übertrugen wir ganz junge Larven aus Arbeiterzellen und stellten das so vorbereitete Versuchsobject in eine inutterlos und brutlos gemachte, kleine Colonie ein. Viele Larven verschwanden. Nach einigen Tagen konnten wir $17 \%$ Mutterthiere, $46 \%$ Drohnen und $37 \%$ Arbeitsbienen feststellen.

Die genauen Angaben, vor Allem auch Zeitangaben, finilen sich in "Nördlinger Bienenzeitung“, Jahrg. 1898 S. 242. )

In ihrer Umbildungsfäligkeit unterscheiden sich Arbeiterlarven wesentlich von Larven mit der Entwicklungsrichtung von Geschlechtsthieren, die in Mutter- und Drohnenzellen unter normalen Coloniezuständen heranwachsen. So viele Versuche ich auch angestellt habe, aus ganz jungen Larven derart andere Thierformen heranbilden zu lassen: stets fielen sie negativ aus. 0 . vom Rat aber hat den positiven Beweis durch anatomische Untersuchung dafür erbracht, dass nur geschlechtliche Miss- und Rückbildungen entstehen, wenn die Arbeiter versuchen, aus einer Drohnenlarve nachträglich noch eine Mutterbiene heranzubilden. Der Geschlechtscharakter wahrer Geschlechtsthiere muss daher von vornherein bei ihnen eine derart bestimmte Richtung einschlagen, dass eine Umwandlung nicht mehr möglich ist, sobald sie ins Larvenstadium eingetreten sind. Vor Eintritt dieses Stadiums werden aber durch die Arbeiter niemals Zellenumformungen zur Heranbildung von Mutterbienen vorgenommen, die unter Normalverhältnissen den Ausgangspunkt für die solchen Thieren entsprechende Beeinflussung bilden.

Bei den Honigbienen existiren hiernach zwei verschiedene Geschlechtsbildungsformen neben einander, die ihre Herkunft nur der eigenartigen Uebertragung der Geschlechtsfunctionen auf zwei verschiedene Thierformen verdanken. ${ }^{2}$ )

1) Trotzdem hat Petrunkewitsch in seiner erwähnten Arbeit die Behauptung ausgesprochen, dieser Versuch habe keine Beweiskraft, da die genauen Zeitangaben mangelten.

2) Ich vermuthe, dass diese Entwicklungweise mit der Herkunft der Biene aus einem Stamme hermaphroditer Würmer in Zusammenhang steht, ja, dass sich 
Aber ein Drittes lehrt uns noch dieser Versuch:

Die Bienenzelle in ihrer heutigen Gestaltals Regulator der Geschlechtsentwicklung bei den Bienennachkommen kann nichts Ursprüngliches, sondern muss etwas Erworbenes sein.

Hätten die Zellen von Urbeginn an den heutigen Zwecken gedient, so könnten ganz unmöglich die Bienen in den Drohnenzellen Arbeiter heranziehen. Nachdem sie derselben aber die wahrhaft geschlechtsbestimmenden Elemente imprägnirt haben, gelingt ihnen das. Wenn dann nach Wegnahme der Mutter aus der Colonie mit diesen Pseudoarbeiterzellen namentlich die Drohnen wieder in grosser Zahl hervorgehen, so ist dieser Vorgang leicht zu verstehen. Brauchen doch die Bienen, um ihren Trieb nach Erzielung von Drohnen zu befriedigen, nur die vorliegenden Zellen ihrer wahren Bestimmung gemäss wieder zu behandeln.

Viel schwieriger ist es schon, aus dem vorliegenden Material Mutterthiere zu erzielen, denn das erfordert den Umbau der Zellen. Wenn aber dennoch auch bei den natürlichen Schwarmvorgängen meist ziemlich viele Mutterbienen angelegt werden (ich habe deren eiumal 87 in einer Colonie gezählt), obschon sie sich dem Bau der Gruppenzellen als Ganzes nicht einfügen lassen, so dürfen wir hieraus mit höchster Wahrscheinlichkeit schliessen: Es ist nur ein Ergebniss des Entwicklungsverlaufs der Bienencolonie, wenn heute in derselbennormaler Weiseanstatt vieler Weibchen nureinesgeduldetwird. Habe ich doch in diesem Frühjahr wieder auf meinem Stande eine Colonie entdeckt, in welcher zwei rüstige Mütter auf derselben Wabe friedlich Eier nebeneinander ablegten.

Sehen wir in den eintretenden Erscheinungen nach Wegnahme der Mutter sich das Triebleben der Bienen concentriren auf Heranzucht von Geschlechtsthieren, so möge der nächste Versuch zeigen, wie sich diesem Triebe diejenigen so überraschend unterordnen, welche wir in der Normalcolonie zum Ausdruck gelangen sehen.

\section{Versuch XII.}

Im Monat Mai entnehme man einer Normalcolonie die Mutterbiene und alle Brutwaben bis auf eine, deren Larven aber schon nur durch diesen Zusammenhang die Entstehung von getrennten Geschlechtern erklären lässt. 
alle eingeschlossen sind. Den hierdurch beschränkten Sitz für die vielen Bewohner erweitere man durch Einfügen von Rähmchen mit Wabenanfängen. Für die Regel schon am folgenden Tag wird man eine grössere Anzahl von Mutterzellen, namentlich an den Wabenanfängen, vorfinden. Bei guter Tracht wird man auch neue Gruppenzellen an den Wabenanfängen entstehen sehen, aber ausschliesslich Drohnenzellen. Arbeiterzellen errichten die entmutterten Bienen erfahrungsgemäss auch in solcher Lage niemals, wo sie im Normalzustand solche stets aufführen würden.

An Zellen fehlt es nun nicht mehr zur Heranzucht von Geschlechtsthieren, wohl aber an den nöthigen Eiern zur Pflege. Der Weg zur Erlangung solcher ist zu interessant und lehrreich, als dass ich nicht versuchen sollte, etwas eingehender darüber zu sprechen.

Beobachtet man in einer Normalcolonie die Vorgänge beim Legen des Mutterthieres, so gewahrt man, wie stets eine Anzahl von Arbeitern bereit steht, mit den Köpfen der Mutter zugekehrt, um - man gestatte mir einmal, die mir zutreffend erscheinende Bezeichnung auszusprechen - um die ihnen specifisch eigene Form der Geschlechtsbefriedigung an dem Mutterthiere auszuüben. Hat die Mutter vier bis fünf Eier in raschem Tempo hintereinander abgelegt, so ruht sie etwas, und nun reichen ihr die nächststehenden eifrig den Rüssel oft in grösserer Zahl nach einander. Auf diesem Wege wird das Mutterthier zu einer höchst ergiebigen Absatzquelle für die Production der Arbeiter an Bildungsstoffen.

In unserem Versuche aber fehlt die Mutterbiene, und da wird man denn jetzt beobachten können, wie sich die Thiere selbst unter einander als Geschlechtsthiere behandeln durch gegenseitiges Darreichen der Bildungsstoffe. Die Wirkung ist eine geradezu erstaunliche. Oft schon nach wenigen Tagen vermögen dieselben Thiere, bei welchen man laut Untersuchungsergebnissen von Le uckart in den wenigen Eiröhren für die Regel keine Spur von Eianlagen antrifft, thatsächlich Eier zu produciren. Wo legen sie dieselben hin? Nun, wenn meine Anschauungen richtig sind, so müssen sie dieselben dahin bringen, wo Zellen für Geschlechtsthiere angelegt wurden. So geschieht es denn auch, und niemals wird man zu Anfang einer solchen Entwicklungserscheinung dann Eier in Arbeiterzellen antreffen, wenn innerhalb des Bienensitzes Drohnenzellen vorhanden sind, und die Raumverhältnisse das Anlegen von Mutterzellen gestatteten. Haben sie längere Zeit vergeblich versucht, aus diesen 
unvollkommenen Eiern Mütter heranzubilden, und die Zahl der Eiproducenten hat sich in's Unübersehbare vermehrt, dann legen sie auch Eier in Arbeiterzellen ab. .Verliert eine Colonie mit eierlegenden Arbeitern innerhalb der nächsten zwei Monate nicht zu viele Arbeiter, so scheinen sie nach dieser Zeit auch wieder Arbeiterzellen zu bauen, falls die Trachtverhältnisse hierzu anregen. Fin solcher Fall ist mir wenigstens ein Mal begegnet.

Diejenigen Versuche, welche mir die absolute Gewissheit der Richtigkeit meiner Annahme gebracht haben, wonach das Mutterthier nur befruchtete Eier nach erfolgter Begattung ablegeu kann, sind folgender Art gewesen: In Arbeiterzellen von Colonien mit nur eierlegenden Arbeitern wurden hunderte von soeben durch normale Mütter in Normalverhältnissen den Drohnenzellen einverleibten Eiern künstlich übertragen. Dass das Erzielen von Lebewesen aus übertragenen Eiern nur eine Glückssache, ein günstiger Zufall sein kann, folgt aus der Entwicklungsweise derselben.

Die Verklebuug derselben mit dem Zellenboden reicht gerade aus, um ihrer Bearbeitung durch die Munditheile der Arbeiter Stand zu halten. Erfolgt nun deren Ablösung vom Boden und die Uebertragung in andere Zellen, so kan sie für die Regel nicht mehr hinreichen, um der Berührung durch die ausgeschiedenen Säfte Seitens der Biene ohne Ablösung vom Zellenboden genügend Widerstand zu leisten. Die Eier bleiben vielmehr an den Mundtheilen der Arbeiter hängen und werden von ihnen aufgezehrt.

Trotzdein habe ich in Folge beharrlicher Versuche aus Tausenden

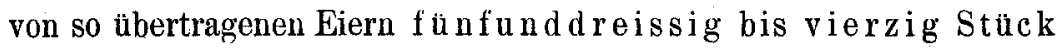
Arbeitsbienen gewonnen.

Diese Versuchsergebnisse müssen für jeden entscheidend sein, der mit dem Entwicklungsmechanismus in der Bienencolonie vertraut ist und logisch zu schliessen vermag, denn:

Da aus dem unbefruchteten Bienenei niemals etwas Anderes als die männliche Bienenform hervorgeht, da aus dem in die Drohnenzelle abgelegten Ei unter Normalzuständen, welchen diese übertragenen Eier entstammten, niemals etwas Anderes entsteht, als die normale Drohne, so folgt hieraus, dass die von mir übertragenen Eier befruchtet waren, und dass somit auch normale Drohneneier befruchtet sind.

Ausserdem ist es M y er und Hensel sogar gelungen, aus eben 
in Drohnenzellen abgesetzten Eiern echte Mutterthiere durch Uebertragung derselben in Mutterzellenanfänge zu erzielen. ${ }^{{ }^{\prime}}$ )

Wie ich übrigens bestimmt glaube, sind die Zeiten vorüber, welche mir so aussergewöhnliche Opfer auferlegten, um mich mit absoluter Gewissheit vom Befruchtetsein normaler Drohneneier überzeugen zu können. Dem schon genannten Bienenforscher Petilliot gebührt das Verdienst, eine Methode dieses Nachweises entdeckt $z u$ haben, die verhältnissmässig leicht auszuführen ist. Durch dieses Verfahren ist es uns möglich gemacht, auch obne Vornahme von Eiübertragung aus solchen Eiern Arbeiter zu erzielen, die unter völlig normalen Verhältnissen in Drohnenzellen abgelegt werden, und die an Ort und Stelle erfahrungsgemäss stets nur Männchen ergeben würden. Mit Rücksicht auf die Wichtigkeit der Sache mögen die betreffenden Ausführungen Petilliot's in "Rheinische Bienenzeitung" 1902, S. 151, hier folgen:

„Um dieselbe Zeit setzte ich ein Völkchen auf nur Drohnenbau, um einen Versuch mit Reinzucht zu machen, wenn keine Drohnen mehr sonst sein werden. Nebenbei wollte ich eine Drohnenwabe, in normalem Volk bestiftet, zwischenhängen, um gleichzeitig nach dieser Seite Erfahrungen zu sammeln. Am 1. August fand ich nach vielen vergeblichen Revisionen endlich die gewünschte, durchaus bestiftete Wabe; die Königin hingegen auf der vorherigen Wabe beim Legen. Sehr glücklich war ich also nicht, weil ich die Majestät nicht auf der Versuchswabe selbst legend antraf. ${ }^{2}$ ) Diese in normalem Brutlager bestiftete Drohnenwabe hing ich hinter Absperrgitter ${ }^{3}$ ) in mein Drohnenvölkchen ein.

Am 3. August war unser Verein auf meinem Stande versammelt. Bei dieser Gelegenheit öffnete ich auch das Drohnenvölkchen and zeigte die Brut, wie auch die normal bestiftete Wabe. Es befanden sich in derselben nach zwei Tagen ${ }^{4}$ ) schon viele kleine Maden, die

1) „Bienenzeitung" 1898 S. 274 u. 337.

2) D. h. weil die Eier in Folge ihres Alters schon zu sehr den Einflüssen zur Heranbildung von Drohnen unterworfen waren, wie hervorgeht aus den Zeitangaben über das Erscheinen von Maden und dem Entwicklungsverlauf der Wesen.

3) Absperrgitter ist eine Vorrichtung, die zwar den Arbeitsbienen den $\mathrm{Zu}$ tritt zu der hinten eingehängten Wabe gestattete, nicht aber auch der Mutterbiene, da sie die engen Schlitze dieses allgemein verbreiteten Bienenzuchthülfsmittels in Folge ihres umfangreicheren Thorax nicht passiren kann. D. V.

4) Die normale Entwicklungszeit des Bieneneies beträgt drei Tage. D. V. 
also für den Versuch schon verloren waren. Aber auch noch einige Fier waren vorhanden und Lücken wurden bemerkt. Als ich am 8. August wieder nachsah, war die Wabe grössten Theils mit Honig gefüllt, und ausserdem waren noch flach gedeckelte Zellen, wie einige offene Maden vorhanden. Es machte auf mich den Eindruck, dass ich wohl zwanzig flach gedeckelte Zellen erzielen könnte. Am 9. August fand ich nach genauer Prüfung noch sieben flach gedeckelte (also künftige Arbeiter enthaltende) Zellen vor. Es waren offenbar sehon verschiedene ausgerissen, was am 11. August Abends bestimmt erkannt wurde, weil nur noch fünf standen."

Nach weiteren Mittheilungen Petilliot's wurden die Zellen in Gegenwart zweier Zeugen am 13. August Nachmittags geöffnet. Die fünf Nymphen erwiesen sich in allen Merkmalen als regelrechte und vollkommen entwickelte Arbeiternymphen der entsprechenden Altersstufe.

Dieser Darstellung muss ich noch einige erläuternde Bemerkungen zufügen.

Durch meine umfangreichen Eiübertragungsversuche habe ich festgestellt, dass Eier, die unter normalen Koloniezuständen den Drohnenzellen entnommen wurden, um sich in Bienenzellen weiter zu entwickeln, nach eingetretenem Larvenzustand dann höchst auffallende Störungserscheinungen zeigten, wenn dieselben in den Drohnenzellen den Einflüssen der Arbeiter schon unterstanden batten. Der vordere Körperpol erhebt sich bei so erzielten Larven in gewissen Zeitperioden in ruckweiser Links- und Rechtsdrehung nach der Zellenöffnung hin. Er senkt sich dann wieder zu regelrechter Lage und verharrt längere Zeit in ihr. Dann wiederholt sich die Erscheinung.

Um eine solche Larve ist es aber geschehen, sobald während der Zeit solcher abnormer Bewegungsvorgänge eine fütternde Biene eindringt. Ein Reiz trifft das Thier dann, der in den Maschinerieplan nicht passt. Es packt den Fremdkörper und zerrt ihn aus der Zelle.

Ueber die Ursache des Verschwindens der Larven auch noch nach dem Verschluss der Zelle sei Folgendes ergänzt: Die Larve in Bienen- und Drohnenzellen rotirt während der erstern fünf Tage parallel dem Zellenboden. Um die noch vorhandenen Futterreste auf demselben zu erlangen; kehrt sie nach Ablauf dieser fünf Tage im Verlaufe einiger Stunden die beiden Körperpole dem Boden zu. Damit wendet sich der Rücken dem Ausgang der Zelle zu, und 
jetzt erfolgt allmählich der: Zellenschluss. Die Larve tritt jetzt die mehrere Tage währende Zellenlängsrotation in der geschlossenen Zelle an ${ }^{1}$ ). Die Wachsthumsstörungen, welche durch die schon vorausgegangene, andere Beeinflussung veranlasst werden, haben bei solchen Larven im Gefolge, dass der Verschlussdeckel mit dem Kopftheil durchbrochen wird. Zwei, drei Bewegungsstösse von der inneren Körpermasse her genügen, um das Schicksal der Larve zu besiegeln. Sie wird von den Bienen gepackt und herausgezerrt.

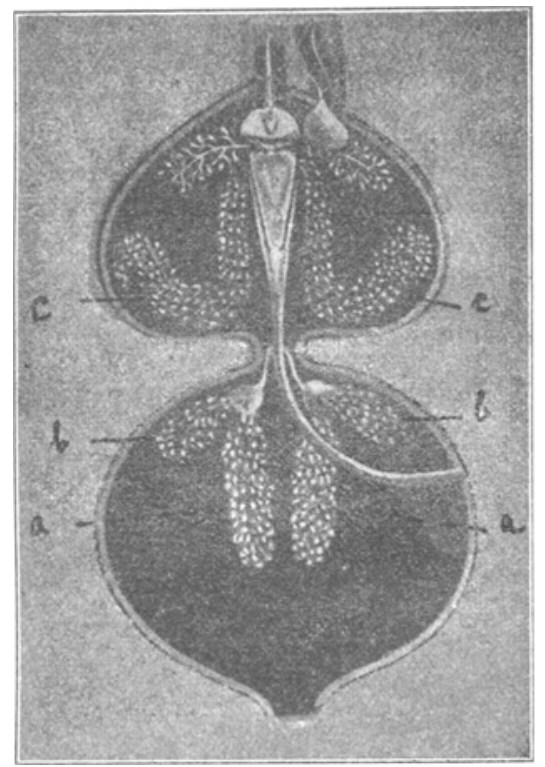

Fig. 1.

Solche Erscheinungen treten aber niemals auf bei der Entwicklung von unbefruchteten Eiern unter gleichen oder ähnlichen, künstlich herbeigefübrten Entwicklungsmodificationen. Daher glaube ich behaupten zu dürfen: Und hätte Petilliot durch seinen Versuch auch nur eine einzige Arbeiterin auf dem eingeschlagenen Wege erzielt, er hätte damit allein schon den ausreichenden Beweis für meine Behauptung erbracht: Auch die normalen Drohneneier sind befruchtet.

1) Auf Darstellung đer höchst interessanten Bewegungs- und Begleiterscheinungen dieser Drehungsweise kann ich leider mit Rücksicht auf den Umfang der Arbeit nicht eingehen. 
106 Ferd. Dickel: Die Ursachen der geschlechtl. Differenzirung etc.

In kurzer Zusammenfassung , ergeben aber die obigen Darstellungen: Aus Arbeitereiern kann man Drohnen erziehen und umgekehrt. Die ron der normalen Mutterbiene abgesetzten Eier müssen daher auch alle befruchtet sein, und somit kann vonihr die Geschlechtsbestimmung nicht abhängig sein. Da manferner durch Secretübertragung die Zukunft des Eies bestimmen kann, so ist dieses das Ausschlaggebende.

\section{Kurzer Nachtrag.}

$\mathrm{Zu}$ Veranschaulichungszwecken gebe ich noch eine schematische Darstellung der bis jetzt bekannten Kopf- und Brustdrüsen der Honigbienen bei. Die Abbildung ist der E. v. L acher'schen anat. Bienentafel Nr. III entnommen. Der Hinterleib wurde bei der photographischen Aufnahme verdeckt, und die zugefügten Buchstaben $a, b, c$ wurden in Uebereinstimmung gebracht mit den in meiner Abhandlung zur Bezeichnung der Drüsen gewählten. 